\title{
Phase and defect evolution in U-N-O system under irradiation
}

Lingfeng He ${ }^{a,}{ }^{*}$, Marat Khafizov ${ }^{b}$, Chao Jiang ${ }^{a}$, Beata Tyburska-Püschel ${ }^{\text {c,g }}$, Brian J. Jaques ${ }^{\text {d }}$, Pengyuan Xiu ${ }^{\text {a }}$, Peng Xu ${ }^{\text {a,e }}$, Mitchell K. Meyer ${ }^{\text {a }}$, Kumar Sridharan ${ }^{c}$, Darryl P. Butt ${ }^{\mathrm{f}}$, Jian Gan ${ }^{\text {a }}$

${ }^{a}$ Idaho National Laboratory, Idaho Falls, ID 83415, USA

${ }^{b}$ The Ohio State University, Columbus, OH 43210, USA

${ }^{c}$ University of Wisconsin-Madison, Madison, WI 53706, USA

${ }^{d}$ Boise State University, Boise, ID 83725, USA

e Westinghouse Electric Company-Nuclear Fuel, Hopkins, SC 29061, USA

${ }^{f}$ The University of Utah, Salt Lake City, UT 84112, USA

${ }^{g}$ Dutch Institute for Fundamental Energy Research, 5612 AJ Eindhoven, the Netherlands

*Corresponding author

E-mail address: Lingfeng.He@inl.gov

\begin{abstract}
Uranium mononitride (UN) with $5 \mathrm{wt} . \%$ uranium dioxide $\left(\mathrm{UO}_{2}\right)$ is used as a model system to study the phase and defect evolution under proton irradiation in nitride-oxide composite. Phase composition, crystallographic orientation relationships (ORs) and dislocation loops were characterized using X-ray diffraction, transmission electron microscopy, and energy dispersive Xray spectroscopy techniques. Proton-irradiation at elevated temperatures promoted the transformation of $\mathrm{UN}$ into uranium sesquinitride $\left(\mathrm{U}_{2} \mathrm{~N}_{3}\right)$ and $\mathrm{UO}_{2}$ phases. $\mathrm{U}_{2} \mathrm{~N}_{3}$ and $\mathrm{UO}_{2}$ formed a fully coherent structure with two ORs: $\{002\} \mathrm{U}_{2} \mathrm{~N}_{3} \|\{002\} \mathrm{UO}_{2}$ and $[001] \mathrm{U}_{2} \mathrm{~N}_{3} \|[001] \mathrm{UO}_{2}$; $\mathrm{U}_{2} \mathrm{~N}_{3}\{101\} \| \mathrm{UO}_{2}\{101\}$ and $\mathrm{U}_{2} \mathrm{~N}_{3}[101] \| \mathrm{UO}_{2}[101]$ due to low lattice misfit $(2.3 \%)$ and low interfacial energy $\left(127 \mathrm{~mJ} / \mathrm{m}^{2}\right)$. Observed oxidation of UN and coherent interface are consistent with density-functional theory calculations which suggest lower energy for oxidized configuration
\end{abstract}


and low energy of the interface. The dislocation loops grew while their number density decreased with the temperature and dose. The loop size was over three times larger in two nitride phases than that in $\mathrm{UO}_{2}$, while the number density was one order of magnitude higher in $\mathrm{UO}_{2}$ than in nitride phases. Loop density and diameter were analyzed using a kinetic rate theory that considers stoichiometric loop evolution. This analysis led to the conclusion in all compounds loop growth is governed by mobility of uranium interstitials, and enabled measurement of diffusion coefficients of uranium interstitials and non-metal interstitials and vacancies. This analysis provided a comparative study of early stage of microstructure evolution under irradiation which has implications for use of this mixture as advanced fuel in nuclear energy systems.

\section{Introduction}

The efficiency of energy generation and utilization systems depends on material property changes influenced by microstructure evolution under extreme operating conditions. Particularly in environment where materials are subjected to a flux of energetic neutrons and charged particles, degradation of mechanical properties [1,2], corrosion/oxidation resistance [3-7], and thermal conductivity [8-10] have been associated with defect generation, and compositional redistribution in the microstructure. Energetic particles can knock atoms out of their lattice site and create point defects (vacancies, interstitials). These point defects can evolve into extended defects such as dislocation loops, cavities, or stacking fault tetrahedra [11-15]. In some cases, element segregation, phase transition and chemical interactions can be induced by irradiation [16-20]. The effects of irradiation in materials are strongly related to their crystal structure and chemical composition $[21,22]$. Therefore, it is of scientific and technical importance to understand the phase and defect

evolution of materials under irradiation environments. Of particular interest are mixed phase 
systems that leverage desired physical and chemical behavior of individual phases. While a vast body of literature exists for radiation damage in composites for structural applications, there are relatively few fundamental studies on duel fuel materials such as uranium mononitride (UN)uranium dioxide $\left(\mathrm{UO}_{2}\right)$.

UN has higher uranium density, and hence higher performance for a given volume of fuel under irradiation compared with $\mathrm{UO}_{2}[23,26]$. It also has a higher thermal conductivity which is desired in the reactor core to minimize thermal gradients. $\mathrm{UN}$ and its mixed nitrides (e.g. $(\mathrm{U}, \mathrm{Pu}) \mathrm{N})$ and composites are being considered as nuclear fuels or fuel components (e.g. tristructural isotropic particles) for advanced reactors such as liquid metal-cooled fast reactors and high-temperature gascooled reactors as well as light water reactors [27-33]. However, UN has unproven performance in accident scenarios, such as a fuel cladding breach where the fuel pellet would be exposed to water coolant or steam [34-39]. It has been proposed that the addition of secondary phases, such as $\mathrm{UO}_{2}$ and $\mathrm{U}_{3} \mathrm{Si}_{2}$, can mitigate the chemical reaction of $\mathrm{UN}$ with water or steam [40-43].

In the U-N system, there are four phases at ambient pressure, namely, $U N, \alpha-U_{2} N_{3}, \beta-U_{2} N_{3}$ and $\mathrm{UN}_{2}$ [44-49]. UN has a NaCl-type face centered cubic (fcc) structure, which is composed of an fcc array of $\mathrm{U}$ atoms with $\mathrm{N}$ atoms at the octahedral sites. Pure $\mathrm{UN}$ is typically slightly substoichiometric, and has a maximum N-rich composition of $\mathrm{UN}_{0.995}[45,47]$. Sesquinitride $\alpha$ $\mathrm{U}_{2} \mathrm{~N}_{3}$ is body-centered cubic (bcc) with $\mathrm{Mn}_{2} \mathrm{O}_{3}$-type structure and $3 / 4$ of tetrahedral sites (total of eight) in $\alpha-\mathrm{U}_{2} \mathrm{~N}_{3}$ sublattice are occupied by $\mathrm{N}$ atoms. Interstitial $\mathrm{O}$ atoms may enter into the unoccupied tetrahedral sites or replace $\mathrm{N}$ atoms in $\alpha-\mathrm{U}_{2} \mathrm{~N}_{3}$ sublattice to form $\mathrm{U}_{2} \mathrm{~N}_{3+\mathrm{x}} \mathrm{O}_{\mathrm{y}}$ [51]. $\beta$ $\mathrm{U}_{2} \mathrm{~N}_{3}$ is hexagonal with a $\mathrm{La}_{2} \mathrm{O}_{3}$-type structure. The $\beta-\mathrm{U}_{2} \mathrm{~N}_{3}$ is a high temperature phase, stable only above $800{ }^{\circ} \mathrm{C}[44,45]$, and therefore will not be addressed in detail in this manuscript. 
$\mathrm{UN}_{2}$ has a $\mathrm{CaF}_{2}$-type fcc structure with all the $\mathrm{N}$ atoms occupying eight tetrahedral sites in $\mathrm{UN}_{2}$ sublattice. This is similar to the $\mathrm{UO}_{2}$ structure, which has $\mathrm{O}$ atoms at tetrahedral sites. $\alpha-\mathrm{U}_{2} \mathrm{~N}_{3}$ and $\mathrm{UN}_{2}$ exhibit a wide range of compositions by virtue of gaining or losing $\mathrm{N}$ in tetrahedral sites, so that they are denoted as $\alpha-\mathrm{U}_{2} \mathrm{~N}_{3+\mathrm{x}}(0 \leq \mathrm{x} \leq 0.5)$ and $\mathrm{UN}_{2-\mathrm{x}}(0 \leq \mathrm{x} \leq 0.25)[48,49]$. Since the apparent crystallographic change from $\mathrm{CaF}_{2}$-type fec $\mathrm{UN}_{2}$ to $\mathrm{Mn}_{2} \mathrm{O}_{3}$-type bec $\alpha-\mathrm{U}_{2} \mathrm{~N}_{3}$ occurs at a composition of $\mathrm{UN}_{1.75}$, it is common to refer to compounds with stoichiometry above $\mathrm{UN}_{1.75}$ as $\mathrm{UN}_{2}$ and below it as $\alpha-\mathrm{U}_{2} \mathrm{~N}_{3}[50]$. The reaction path shows that the $\mathrm{UN}_{2}$ decomposition to $\alpha-\mathrm{U}_{2} \mathrm{~N}_{3}$ starts at about $675^{\circ} \mathrm{C}$, and the second decomposition to $\mathrm{UN}$ begins near $975^{\circ} \mathrm{C}$ in $\mathrm{N}_{2}$ atmosphere [49]. The sintering of UN pellets and their composites is done at temperatures well above $975{ }^{\circ} \mathrm{C}$ at which point the decomposition of $\mathrm{UN}_{2}$ phase is fully completed.

The phase evolution during oxidation of UN has been investigated since 1960s [52-56]. UN is converted to $\mathrm{U}_{2} \mathrm{~N}_{3}$ and $\mathrm{UO}_{2}$ as intermediate oxidation products and ultimately to $\mathrm{U}_{3} \mathrm{O}_{8}$ or $\mathrm{UO}_{3}$. $\mathrm{U}_{2} \mathrm{~N}_{3}$ is sandwiched between the $\mathrm{UO}_{2}$ surface layer and the $\mathrm{UN}$ single crystal matrix after oxidation. Both $\mathrm{U}_{2} \mathrm{~N}_{3}$ and $\mathrm{UO}_{2}$ are epitaxially oriented with respect to the $\mathrm{UN}$ single crystal. The crystallographic orientation relationship (OR) between these three phases as determined by the electron diffraction technique is $\{001\} \mathrm{UO}_{2}\left\|\{001\} \mathrm{U}_{2} \mathrm{~N}_{3}\right\|\{001\} \mathrm{UN}$ and $<100>\mathrm{UO}_{2}\left\|<100>\mathrm{U}_{2} \mathrm{~N}_{3}\right\|<100>\mathrm{UN}$ [53]. Initially the oxidation occurs at the surface of UN according to Eq. (1).

$\mathrm{UN}(\mathrm{s})+\mathrm{O}_{2}(\mathrm{~g})=\mathrm{UO}_{2}(\mathrm{~s})+\mathrm{N}$

The as-generated $\mathrm{N}$ species released during the initial stage of the reaction may be in nascent form, which are presumably interstitial $\mathrm{N}$ atoms occupying tetrahedral sites in UN. N interstitials may 
either escape to the UN surface and from molecular nitrogen gas $\left(\mathrm{N}+\mathrm{N}=\mathrm{N}_{2}\right)$ or react with $\mathrm{UN}$ to form a layer of intermediate $\mathrm{U}_{2} \mathrm{~N}_{3}$, as shown in Eq. (2).

$2 \mathrm{UN}(\mathrm{s})+\mathrm{N}=\mathrm{U}_{2} \mathrm{~N}_{3}(\mathrm{~s})$

However, the oxidation reaction path and mechanism of UN is still speculative, especially in regards to the chemical state of $\mathrm{N}$ species [47].

There are very limited reports on the radiation effect of UN [27,28,57-59]. The mesoscale volume swelling and gas release have been the main focus in UN fuel irradiation studies in reactors $[27,28]$ and there is no detailed microstructural characterization of irradiation induced defects. $\mathrm{Kr}$ and $\mathrm{Xe}$ ion irradiations have been used to study the irradiation effects in $\mathrm{UN}[57,58]$. The radiation damage and its recovery upon thermal annealing were studied by Rutherford backscattering-channeling and transmission electron microscopy (TEM) techniques. The radiation damage consists of small defect clusters, with undefined morphology. TEM examinations have shown only black dots in the ion irradiated UN single crystal at room temperature. At annealing temperatures above $727^{\circ} \mathrm{C}$, the defect clusters dissociated, causing the formation of extended defects, dislocation loops and dislocation lines [58]. Details on defect evolution in UN with respect to irradiation temperature and dose are very scant in the open literature.

In this work, $\mathrm{UN}$ with $5 \mathrm{wt} . \% \mathrm{UO}_{2}\left(\mathrm{UN}-5 \mathrm{UO}_{2}\right)$ was used as a model system to study the phase and defect evolution under ion irradiation. The $\mathrm{UN}-5 \mathrm{UO}_{2}$ was irradiated with $2 \mathrm{MeV}$ proton beam at 400 and $710{ }^{\circ} \mathrm{C}$. The phase changes and associated crystallographic orientation relationships, and extended defects (dislocation loops) in the irradiated samples have been characterized using X-ray diffraction (XRD), multiple TEM techniques, including selected area electron diffraction (SAED), 
high resolution TEM (HRTEM), scanning TEM (STEM), high resolution STEM (HRSTEM) and energy dispersive X-ray spectroscopy (EDS). Density-functional theory (DFT) has also been utilized to understand the phase evolution and phase relationships under irradiation. Kinetic rate equation models have been implemented to analyze loop growth mechanisms and quantify diffusion coefficients for some of the defects.

\section{Experimental}

UN powders were synthesized from depleted $\alpha$-uranium (99.4\% purity, 50 mesh) using a hydride-dehydride-nitride thermal synthesis route [41]. Compacts of $\mathrm{UN}-5 \mathrm{UO}_{2}$ were fabricated using the synthesized $\mathrm{UN}$ powders and $\mathrm{UO}_{2}(99.8 \%$ purity, 50 mesh) from Bio-Analytical Industries Incorporated (Boca Raton, FL). The pellets were sintered for 5 hours at $1900{ }^{\circ} \mathrm{C}$ in an Ar $+100 \mathrm{ppm} \mathrm{N}_{2}$ atmosphere. Details of the sintering process are provided in a previous publication [41]. After sintering, the pellets were immediately transferred to an inert atmosphere glovebox. The detailed microstructure of as-sintered pellet can be found in refs. 41,42 . The grain size of $\mathrm{UN}$ and $\mathrm{UO}_{2}$ were approximately $6.2 \pm 2.5 \mu \mathrm{m}$ and $1.7 \pm 0.9 \mu \mathrm{m}$, respectively.

$\mathrm{UN}-5 \mathrm{UO}_{2}$ samples were irradiated with $2 \mathrm{MeV}$ protons up to fluences of $4 \times 10^{18}$ and $8 \times 10^{18}$ ions $/ \mathrm{cm}^{2}$ at $400{ }^{\circ} \mathrm{C}$ and $710{ }^{\circ} \mathrm{C}$. The pressure in the irradiation chamber was below $10^{-6}$ Torr. Figure 1 shows the SRIM prediction of the damage depth range for the three phases, $\mathrm{UN}, \mathrm{U}_{2} \mathrm{~N}_{3}$, and $\mathrm{UO}_{2}$ in the composite calculated using the full-cascade mode [60] with displacement threshold energy, $E_{\text {th }}$ of $40 \mathrm{eV}$ for $\mathrm{U}, 25 \mathrm{eV}$ for N, and $20 \mathrm{eV}$ for $\mathrm{O}[61,62]$. The irradiation resulted in a relatively flat damage profile from the surface to a depth of $15 \mu \mathrm{m}$ in the composite. Microstructural observation was performed on a cross-section area at a depth less than $10 \mu \mathrm{m}$ where the average damage in $\mathrm{UN}, \mathrm{U}_{2} \mathrm{~N}_{3}$, and $\mathrm{UO}_{2}$ was $0.63,0.49$ and $0.55 \mathrm{dpa}$, respectively in this region at the final fluence of $8 \times 10^{18}$ ions $/ \mathrm{cm}^{2}$. The proton flux was maintained at $5.2 \times 10^{13}$ 
ions $/\left(\mathrm{cm}^{2} \mathrm{~s}\right)$ for the low-temperature irradiation and $7.5 \times 10^{13} \mathrm{ions} /\left(\mathrm{cm}^{2} \mathrm{~s}\right)$ for the high temperature irradiation resulting in a damage rate of $4.1 \times 10^{-6}$ and $5.9 \times 10^{-6} \mathrm{dpa} / \mathrm{s}$, respectively for UN. The sample temperature was monitored by two thermocouples attached diagonally to the sample holder. Additionally, the uniformity of temperature was controlled by means of IR camera. Both thermocouples measured a nearly even temperature throughout the experiment.

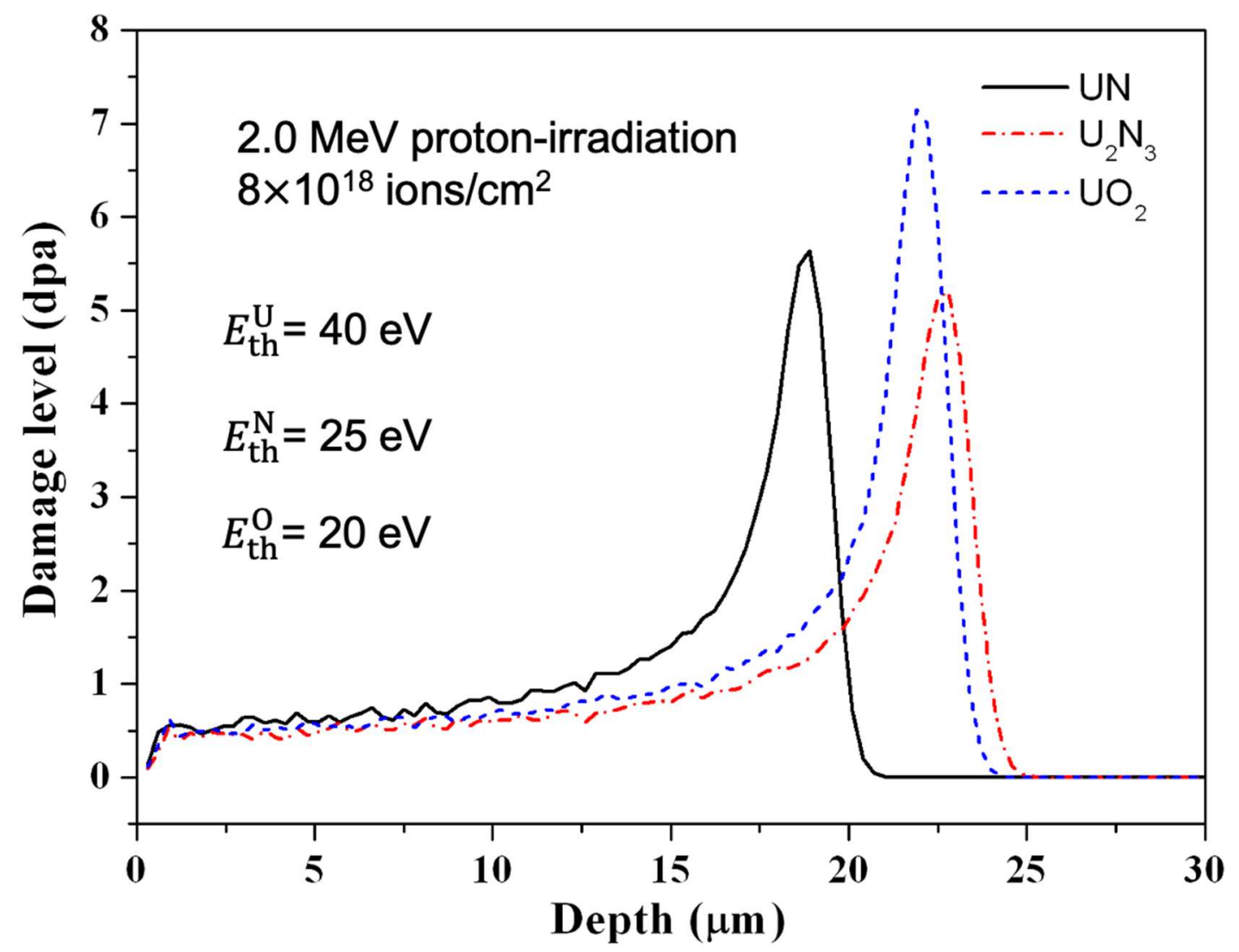

(color online) Figure 1. Damage profile in $\mathrm{UN}, \mathrm{U}_{2} \mathrm{~N}_{3}$, and $\mathrm{UO}_{2}$ irradiated with $2 \mathrm{MeV}$ protons up to a fluence of $8 \times 10^{18}$ ions $/ \mathrm{cm}^{2}$ calculated using full-cascade mode in SRIM. Threshold energies $\left(E_{\mathrm{th}}\right)$ for $\mathrm{U}, \mathrm{N}$ and $\mathrm{O}$ were 40,25 and $20 \mathrm{eV}$, respectively for this calculation.

$\mathrm{XRD}$ characterization of the pristine and irradiated $\mathrm{UN}-5 \mathrm{UO}_{2}$ composite was performed to investigate the phase content after irradiation and corresponding lattice constant. The XRD analysis of all samples was performed on Bruker D8 Discovery, at $50 \mathrm{kV}$ and $1000 \mu \mathrm{A}$, using $\mathrm{Cu}$ 
anode with $\lambda=1.54184[\AA] .0 .3 \mathrm{~mm}$ incident slit and a $0.3 \mathrm{~mm}$ collimator in combination with the Montel mirror and Soller mount were used. The 2D Vantec 500 detector was located at a distance of $200 \mathrm{~mm}$ from the sample. The $2 \theta-\theta$ scans were taken in the range of $22^{\circ}-70^{\circ}$. In order to include the maximum number of grains in the XRD analysis, the $\mathrm{x}-\mathrm{y}$ rastering $(1 \mathrm{~mm}$ by $1 \mathrm{~mm}, \mathrm{x}$-speed: $0.1 \mathrm{~mm} / \mathrm{s}$, y-speed: $0.2 \mathrm{~mm} / \mathrm{s})$ with simultaneous phi rotation $\left(360^{\circ}\right.$, speed $\left.72^{\circ} / \mathrm{s}\right)$ was performed. All spectra were stripped of $\mathrm{K} \alpha_{2}$ line but the background was not removed. Identical parameters were used for XRD analysis of all the samples. The diffraction peaks were identified using the Inorganic Crystal Structure Database (ICSD) [63]. The penetration depth (defined as the depth at which the intensity of the radiation inside the material falls to $1 / \mathrm{e}$, about $37 \%$ of its original value at the surface) was calculated as $2.50 \mu \mathrm{m}, 3.35 \mu \mathrm{m}$ and $3.57 \mu \mathrm{m}$ for $\mathrm{UN}, \mathrm{a}-\mathrm{U}_{2} \mathrm{~N}_{3}$ and $\mathrm{UO}_{2}$, respectively (see Table S1 in the Supplemental Information (SI)), which is much lower than the thickness of the damage zone. Quantitative phase analysis and lattice constant calculation were conducted by the Rietveld method using Materials Analysis Using Diffraction (MAUD) software [64].

To investigate defect structure in $\mathrm{UN}-\mathrm{UO}_{2}$ composite, focused ion beam (FIB) samples were prepared for TEM observations. A lamella was created by coarse trenching $15 \mu \mathrm{m} \times 10 \mu \mathrm{m} \times 1 \mu \mathrm{m}$ sample using the FIB. The sample was then welded to a molybdenum TEM grid for the final FIB thinning. The sample was thinned to roughly $100 \mathrm{~nm}$ using $30 \mathrm{keV} \mathrm{Ga}$ ions and followed by the final cleaning conducted using $2 \mathrm{keV} \mathrm{Ga}$ ions. The FIB lamella was then characterized with a Tenai TF30 TEM at the Center for Advanced Energy Studies and with a Titan Themis 200 TEM with ChemiSTEM capability at the Irradiated Materials Characterization Laboratory facility at Idaho National Laboratory. The EDS data collection was performed using the Bruker ${ }^{\mathrm{TM}}$ Esprit software. 
The measurements of dislocation loop size and number density were conducted manually. Each reported value was calculated based on the average of three measured areas for the number density and loop area per volume measurements and of 50-200 measured features for loop size measurements. Statistical errors were calculated from the measurements and are shown by the error bars in the figures in the paper. The local foil thickness was calculated via the inelastic mean free path (IMFP) measurement using electron energy loss spectroscopy (EELS) technique [65].

\section{Results}

\subsection{Phase characterization}

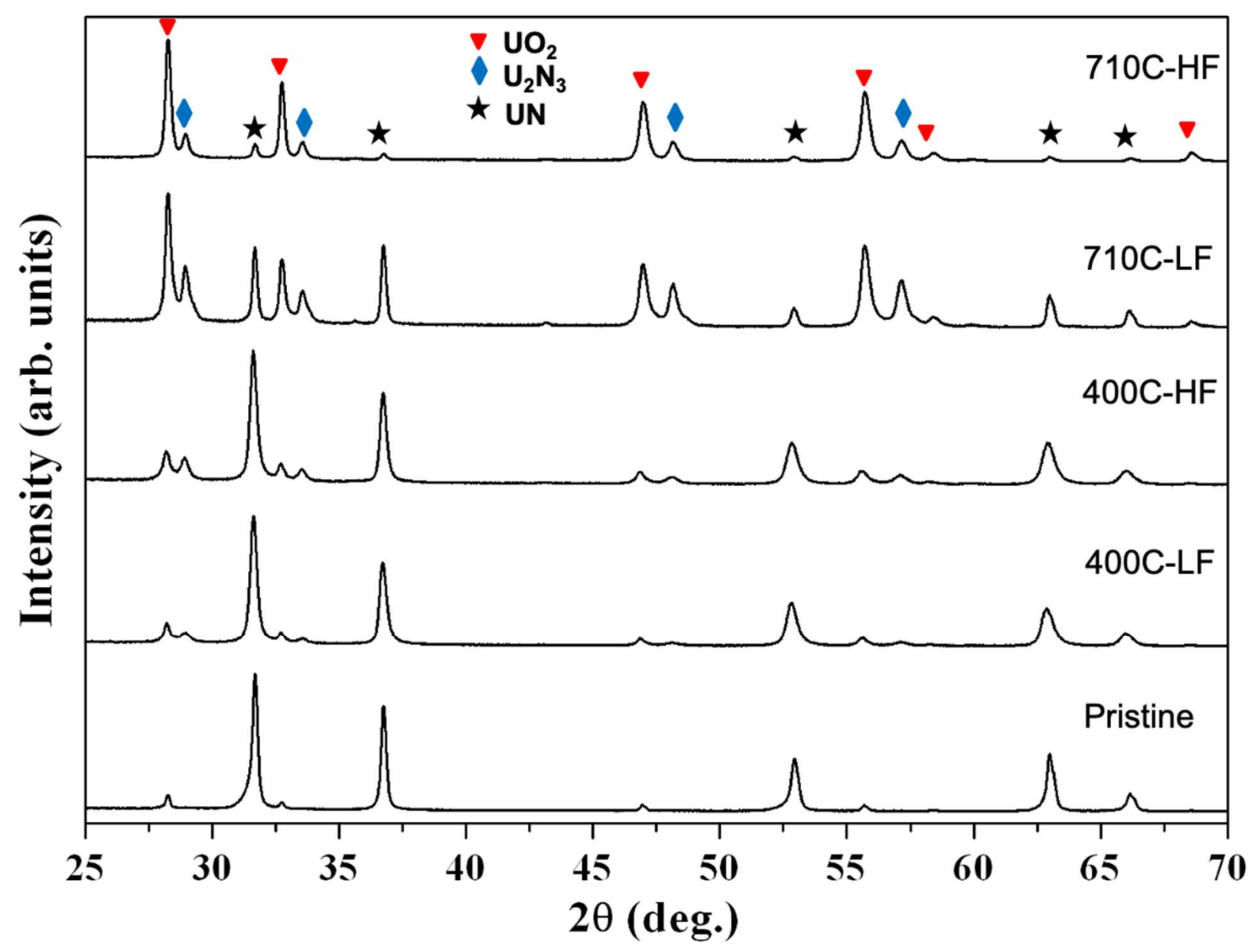


(color online) Figure 2. XRD patterns of $\mathrm{UN}-5 \mathrm{UO}_{2}$ composite before (Pristine) and after $2 \mathrm{MeV}$ proton-irradiation up to fluences of $4 \times 10^{18}(\mathrm{LF})$ and $8 \times 10^{18} \mathrm{ions} / \mathrm{cm}^{2}(\mathrm{HF})$ at $400{ }^{\circ} \mathrm{C}(400 \mathrm{C}-\mathrm{LF}$ and $400 \mathrm{C}-\mathrm{HF})$ and $710^{\circ} \mathrm{C}(710 \mathrm{C}-\mathrm{LF}$ and $710 \mathrm{C}-\mathrm{HF})$.

Table 1 Lattice constant and phase composition (wt.\%) calculated using Rietveld refinement method for the $\mathrm{UN}-5 \mathrm{UO}_{2}$ composites before (Pristine) and after $2 \mathrm{MeV}$ proton-irradiation up to fluences of $4 \times 10^{18}$ (LF) and $8 \times 10^{18}$ ions $/ \mathrm{cm}^{2}$ (HF) at $400{ }^{\circ} \mathrm{C}(400 \mathrm{C}-\mathrm{LF}$ and $400 \mathrm{C}-\mathrm{HF})$ and $710^{\circ} \mathrm{C}$ (710C-LF and 710C-HF). Rwp (\%) is the reliability factor in the Rietveld refinement.

\begin{tabular}{|c|c|c|c|c|c|c|c|}
\hline \multirow[t]{2}{*}{ Sample } & \multicolumn{2}{|l|}{ UN } & \multicolumn{2}{|c|}{$\mathrm{U}_{2} \mathrm{~N}_{3}$} & \multicolumn{2}{|l|}{$\mathrm{UO}_{2}$} & \multirow{2}{*}{$\begin{array}{l}\text { Rwp } \\
(\%)\end{array}$} \\
\hline & $\begin{array}{l}\text { Lattice constant } \\
(\AA)\end{array}$ & wt.\% & $\begin{array}{l}\text { Lattice constant } \\
(\AA)\end{array}$ & wt. \% & $\begin{array}{l}\text { Lattice constant } \\
(\AA)\end{array}$ & wt.\% & \\
\hline Pristine & 4.8892 & 91.7 & 10.684 & 0.6 & 5.4693 & 7.7 & 11.2 \\
\hline 400C-LF & 4.8935 & 79.8 & 10.682 & 7.2 & 5.4738 & 13.0 & 11.9 \\
\hline 400C-HF & 4.8921 & 67.3 & 10.687 & 13.8 & 5.4756 & 19.0 & 11.7 \\
\hline 710C-LF & 4.8929 & 34.7 & 10.689 & 23.6 & 5.4707 & 41.7 & 14.8 \\
\hline $710 \mathrm{C}-\mathrm{HF}$ & 4.8909 & 5.3 & 10.687 & 14.8 & 5.4704 & 79.9 & 8.6 \\
\hline
\end{tabular}

Figure 2 shows the XRD patterns of $\mathrm{UN}-5 \mathrm{UO}_{2}$ composites before and after $2 \mathrm{MeV}$ protonirradiation up to fluences of $4 \times 10^{18}$ and $8 \times 10^{18}$ ions $/ \mathrm{cm}^{2}$ at $400{ }^{\circ} \mathrm{C}$ or $710{ }^{\circ} \mathrm{C}$. The Rietveld refinement of the XRD patterns in Fig. 2 is shown in Figs. S1-S5 in the SI, while Table 1 summarizes the Rietveld refinement results of lattice constants and phase composition. The assintered $\mathrm{UN}-5 \mathrm{UO}_{2}$ composite had $7.7 \mathrm{wt} . \% \mathrm{UO}_{2}$ and $0.6 \mathrm{wt} . \% \mathrm{U}_{2} \mathrm{~N}_{3}$ (balance UN) phases. Proton irradiation at $400{ }^{\circ} \mathrm{C}$ resulted in an increase of both $\mathrm{U}_{2} \mathrm{~N}_{3}$ and $\mathrm{UO}_{2}$ phases in the composite and the quantity of both phases increased with increasing damage level. Under irradiation at $710{ }^{\circ} \mathrm{C}$, the amount of both $\mathrm{UO}_{2}$ and $\mathrm{U}_{2} \mathrm{~N}_{3}$ phases increases significantly compared to that at $400{ }^{\circ} \mathrm{C}$ as well 
as in the pristine, unirradiated sample. $\mathrm{UO}_{2}$ was the dominant phase (79.9 wt.\%) after irradiation up to $8 \times 10^{18}$ ions $/ \mathrm{cm}^{2}$ at $710^{\circ} \mathrm{C}$. Although the accelerator chamber had a vacuum lower than $10^{-6}$ Torr $\left(10^{-4} \mathrm{~Pa}\right)$, the composite still experienced oxidation from the residual oxygen in the chamber, which could be assisted in part by the irradiation. It is noted that the phase change determined by $\mathrm{XRD}$ is only limited to the region within XRD detection depth and the composition below this region is likely very different.
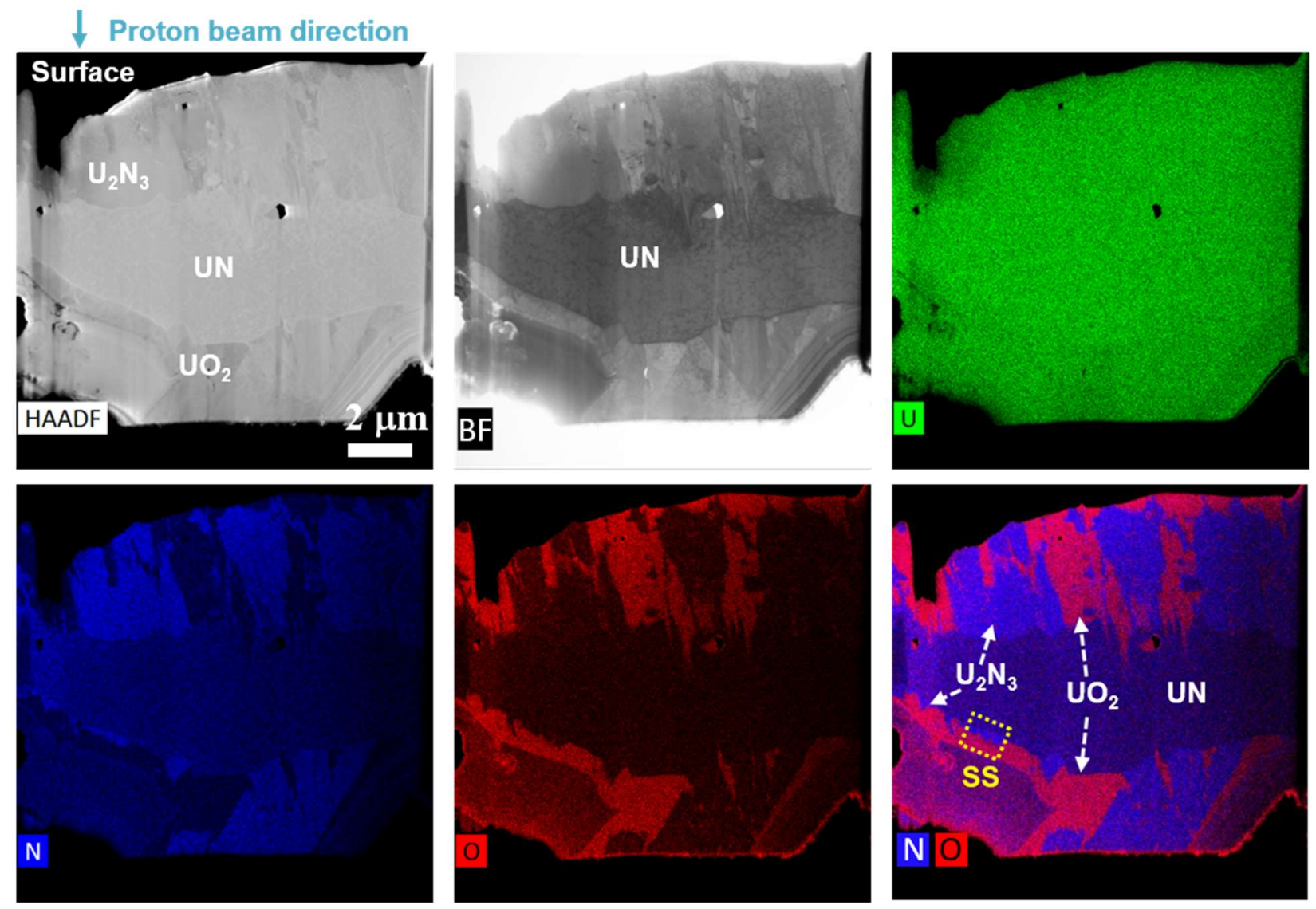

(color online) Figure 3. Low magnification STEM images and EDS elemental maps of $\mathrm{UN}^{-5 \mathrm{UO}_{2}}$ composite after proton irradiation at $710{ }^{\circ} \mathrm{C}$ up to a fluence of $8 \times 10^{18}$ ions $/ \mathrm{cm}^{2}(710 \mathrm{C}-\mathrm{HF})$, showing the coexistence of $\mathrm{UN}, \mathrm{U}_{2} \mathrm{~N}_{3}$, and $\mathrm{UO}_{2}$. In the $\mathrm{O} / \mathrm{N}$ map, the red, blue and dark blue phases are $\mathrm{UO}_{2}, \mathrm{U}_{2} \mathrm{~N}_{3}$ and $\mathrm{UN}$ phases, respectively. The sandwich structure (SS) of $\mathrm{UN} / \mathrm{U}_{2} \mathrm{~N}_{3} / \mathrm{UO}_{2}$ is marked by a yellow dashed rectangular and the proton beam direction is marked by an arrow. 
Figure 3 shows the high angle annular dark field (HAADF) and bright field (BF) STEM images and EDS elemental maps of the $\mathrm{UN}-5 \mathrm{UO}_{2}$ composite after proton irradiation at $710{ }^{\circ} \mathrm{C}$ up to a fluence of $8 \times 10^{18}$ ions $/ \mathrm{cm}^{2}$. The original surface was marked in the Fig. S6. Assuming a flat surface, about tens to hundreds of nm for major part of the lamella got lost during the FIB. Large areas of bright phase and smaller areas of gray phase were observed to coexist in HAADF image. These phases were determined to be $\mathrm{UN}, \mathrm{U}_{2} \mathrm{~N}_{3}$ and $\mathrm{UO}_{2}$, respectively via the combined SAED and EDS analyses. The phase boundaries between $\mathrm{UN}$ and $\mathrm{U}_{2} \mathrm{~N}_{3}$, and between $\mathrm{UN}$ and $\mathrm{UO}_{2}$ are quite discernible, while those between $\mathrm{U}_{2} \mathrm{~N}_{3}$ and $\mathrm{UO}_{2}$ are not distinct, as shown in BF STEM image. The sandwich structure (SS) of $\mathrm{UN} / \mathrm{U}_{2} \mathrm{~N}_{3} / \mathrm{UO}_{2}$ were observed in some regions while the $\mathrm{U}_{2} \mathrm{~N}_{3}$ layers were often interrupted by $\mathrm{UO}_{2}$ phase (top region of the lamella). In the non-irradiated region, side of the same pellet sample (Figure $\mathrm{S} 7$ ), only a very thin $\mathrm{UO}_{2}$ layer ranging from tens of $\mathrm{nm}$ to hundreds of nm formed on UN matrix compared to micron thickness of oxide layers in the irradiated region. It is clearly evident that irradiation accelerates oxidation and phase transformation. In addition, there were numerous dislocations in the composite, especially in the two nitride phases. 

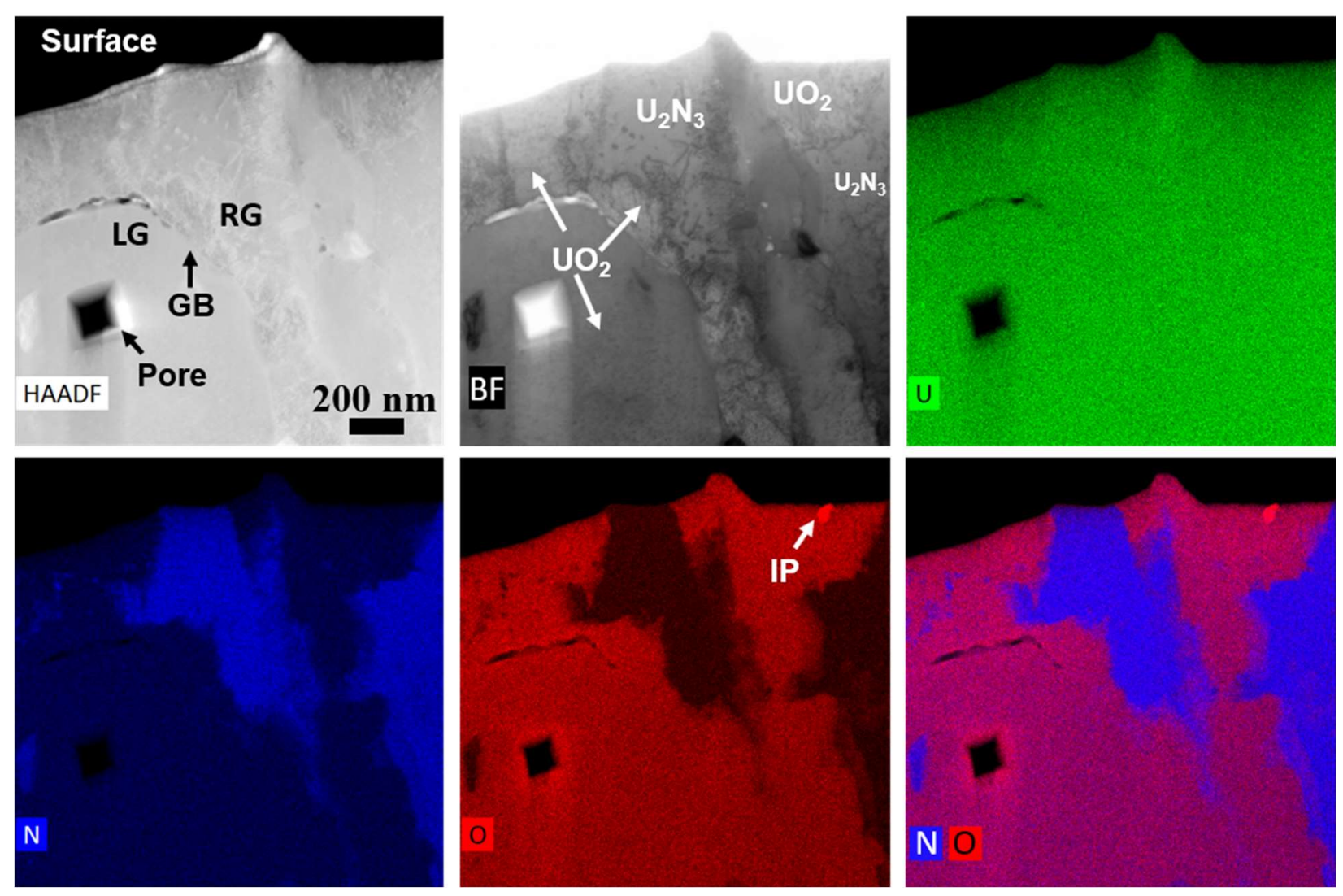

(color online) Figure 4. High-magnification STEM images and EDS elemental maps of UN-5UO composite after proton irradiation at $710{ }^{\circ} \mathrm{C}$ up to a fluence of $8 \times 10^{18} \mathrm{ions} / \mathrm{cm}^{2}(710 \mathrm{C}-\mathrm{HF})$, showing the coexistence of $\mathrm{U}_{2} \mathrm{~N}_{3}$ and $\mathrm{UO}_{2}$. Left grain (LG), right grain (RG), grain boundary (GB), and $(\mathrm{Fe}, \mathrm{Al}, \mathrm{Si})$-rich impurity precipitate (IP) are marked.

To better reveal the phase boundaries between $\mathrm{U}_{2} \mathrm{~N}_{3}$ and $\mathrm{UO}_{2}$, STEM-EDS measurements were performed at higher magnification (Figure 4). In this figure, the left grain (LG) is mainly composed of $\mathrm{UO}_{2}$, while in the right grain (RG) with bigger size there is a large fraction of $\mathrm{U}_{2} \mathrm{~N}_{3}$ co-existing with $\mathrm{UO}_{2}$. The phase boundaries between $\mathrm{UO}_{2}$ and $\mathrm{U}_{2} \mathrm{~N}_{3}$ were revealed by EDS maps, but not readily distinguishable in STEM-BF image, which showed diffraction contrast. There is an impurity precipitate (IP) rich in $\mathrm{Fe}, \mathrm{Al}$ and $\mathrm{Si}$. The IP was very barely observed and it might be induced during the processing of UN pellets. 
Figure 5(a) and 5(b) show the HRTEM images of phase boundaries of $\mathrm{U}_{2} \mathrm{~N}_{3}-\mathrm{UO}_{2}$ in two orientations. Both $\mathrm{U}_{2} \mathrm{~N}_{3}$ and $\mathrm{UO}_{2}$ showed the lattice fringes in both [001] and [101] directions. The fast Fourier transform (FFT) images revealed two crystallographic orientation relationships (ORs): $\{002\} \mathrm{U}_{2} \mathrm{~N}_{3} \|\{002\} \mathrm{UO}_{2} \quad$ and $[001] \mathrm{U}_{2} \mathrm{~N}_{3}\left\|[001] \mathrm{UO}_{2} \quad(\mathrm{OR}-1) ; \mathrm{U}_{2} \mathrm{~N}_{3}\{101\}\right\| \mathrm{UO}_{2}\{101\} \quad$ and $\mathrm{U}_{2} \mathrm{~N}_{3}[101] \| \mathrm{UO}_{2}[101]$ (OR-2). The first OR is the same as the one reported by Sole and van der Walt [53]. These two ORs indicate full structural coherence between $\mathrm{U}_{2} \mathrm{~N}_{3}$ and $\mathrm{UO}_{2}$. Besides the standard pattern of $\mathrm{UO}_{2}, \mathrm{U}_{2} \mathrm{~N}_{3}$ exhibited a regular array of additional weak spots (FFT images and SAED patterns). These weak spots were interpreted as being due to oxygen atoms present in the $\mathrm{U}_{2} \mathrm{~N}_{3}$ lattice in an ordered fashion, forming a superlattice [53]. Due to the small lattice misfit, the diffraction spots of $\mathrm{UO}_{2}$ and $\mathrm{U}_{2} \mathrm{~N}_{3}$ phases near the center spot overlapped very well (Figure 5(e)) but high order of diffraction spots, e.g. (12-40) were observed to split. The coherence of phase boundary between $\mathrm{UO}_{2}$ and $\mathrm{U}_{2} \mathrm{~N}_{3}$ was also observed in the atomic-resolution STEM image as shown in Figure 5(f). The transition of $\mathrm{U}$ atom columns at [001] zone from $\mathrm{UO}_{2}$ to $\mathrm{U}_{2} \mathrm{~N}_{3}$ is relatively smooth and slightly away from [001] zone at phase boundary because of the $2.3 \%$ lattice misfit between the two phases which may generate some strain at the phase boundary. 

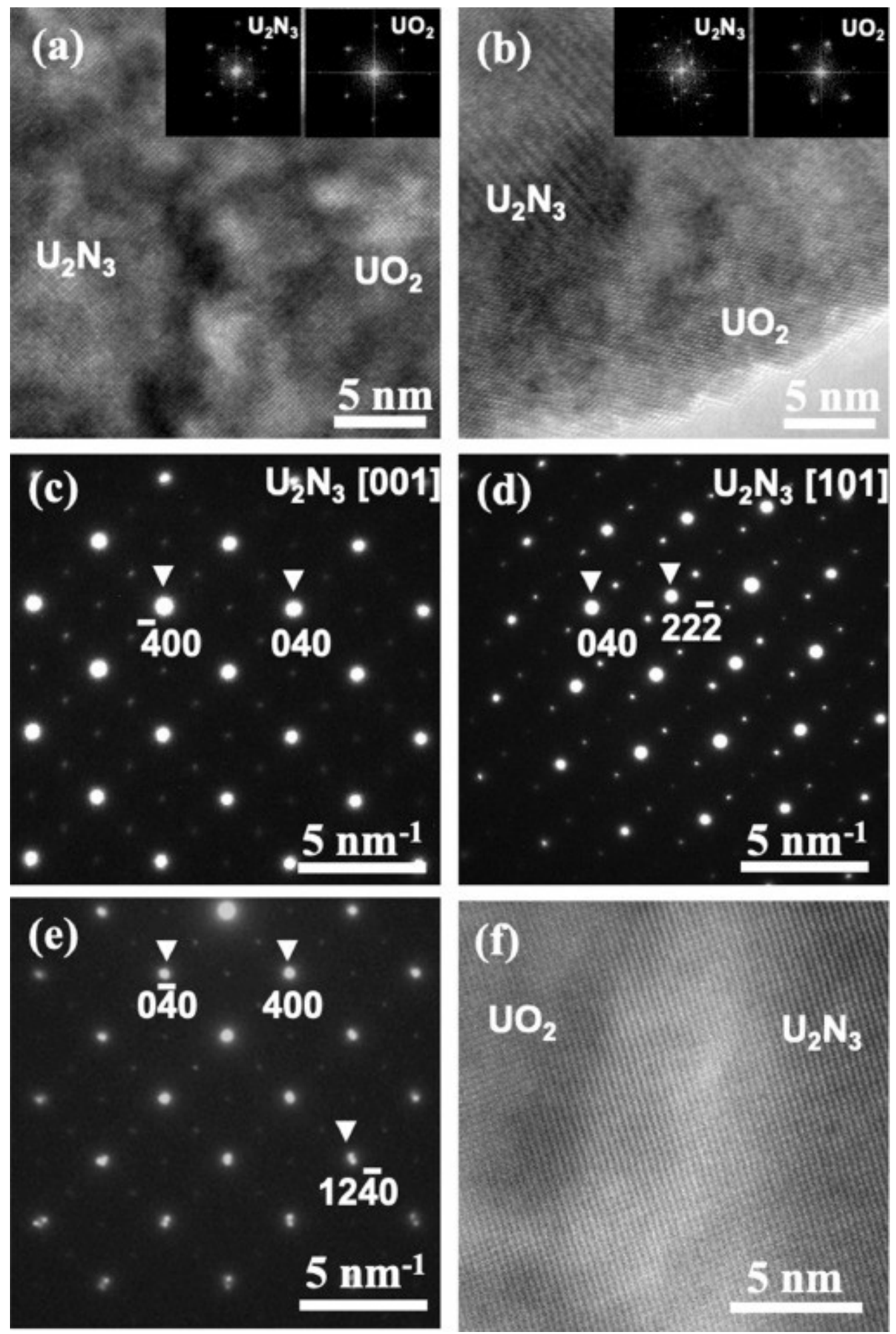

Figure 5. (a) and (b) HRTEM images showing the phase boundaries between $\mathrm{U}_{2} \mathrm{~N}_{3}$ and $\mathrm{UO}_{2}$ at [001] and [101] zones, respectively for $\mathrm{UN}-5 \mathrm{UO}_{2}$ composite after proton irradiation at $710^{\circ} \mathrm{C}$ up 
to a fluence of $8 \times 10^{18}$ ions $/ \mathrm{cm}^{2}(710 \mathrm{C}-\mathrm{HF})$. The insets show the fast Fourier transform (FFT) images at the $\mathrm{U}_{2} \mathrm{~N}_{3}$ and $\mathrm{UO}_{2}$ regions. (c) and (d) $\mathrm{SAED}$ of $\mathrm{U}_{2} \mathrm{~N}_{3}$ at [001] and [101] zones, respectively. (e) SAED of an area including both $\mathrm{U}_{2} \mathrm{~N}_{3}$ and $\mathrm{UO}_{2}$ at [001] zone (only bottom half is shown). (f) HRSTEM image showing atomic $\mathrm{U}$ atom columns at the phase boundary between $\mathrm{U}_{2} \mathrm{~N}_{3}$ and $\mathrm{UO}_{2}$ at $[001]$ zone.
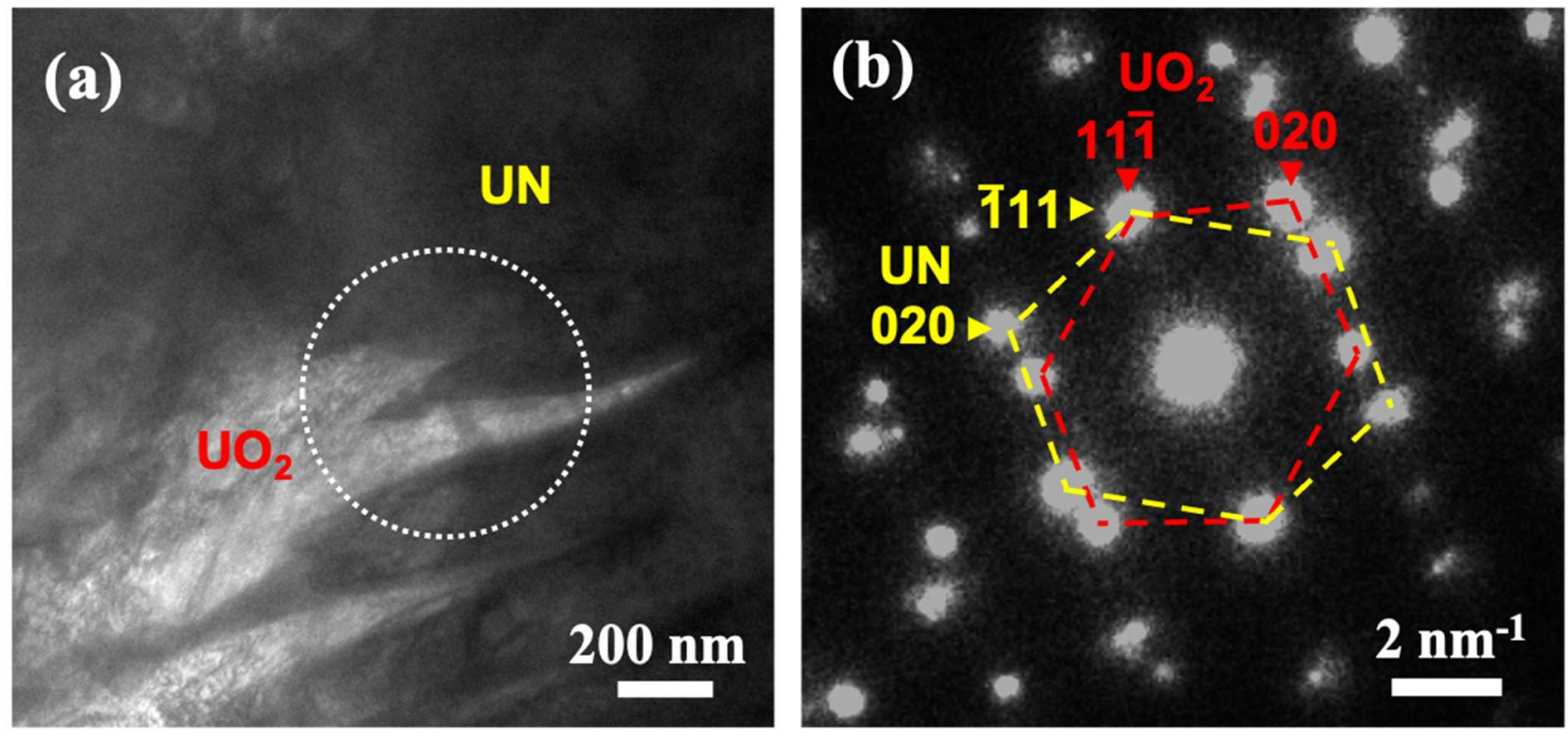

(color online) Figure 6. TEM and SAED images showing that $\mathrm{UN}$ (dark) and $\mathrm{UO}_{2}$ (bright) phases in $\mathrm{UN}-5 \mathrm{UO}_{2}$ composite for $\mathrm{UN}-5 \mathrm{UO}_{2}$ composite after proton irradiation at $710{ }^{\circ} \mathrm{C}$ up to a fluence of $8 \times 10^{18}$ ions $/ \mathrm{cm}^{2}$ (710C-HF). The white dotted circle in (a) shows the selected area for electron diffraction. The crystallographic orientation relationship is [101] UN\|[101] $\mathrm{UO}_{2}$ and (111)UN\|(111) $\mathrm{UO}_{2}$.

Figure 6(a) shows a phase boundary between $\mathrm{UN}$ (dark) and $\mathrm{UO}_{2}$ (bright), which has a sawtoothshape. The SAED including both phases (Figure 6(b)) suggests an OR of [101]UN\|[101] $\mathrm{UO}_{2}$ and (111)UN\|(111) $\mathrm{UO}_{2}$. 


\subsection{Ab initio calculations}

Paralleling experimental study, we performed ab initio calculations using DFT to calculate the thermodynamic driving force for the incorporation of oxygen into the UN lattice. Our calculations employed the all-electron projector augmented wave (PAW) method within the generalized gradient approximation of Perdew, Burke, and Ernzerhof, as implemented in VASP code [66,67]. A cutoff energy of $500 \mathrm{eV}$ and dense k-point meshes were used to guarantee high numerical accuracy. The unit cell volume and internal atomic positions of all structures were fully relaxed using a conjugate-gradient scheme. We obtained the total energies of $\mathrm{O}_{2}$ and $\mathrm{N}_{2}$ gas molecules by placing them in a $10 \AA \times 10 \AA \times 10 \AA$ supercell. Spin polarized calculations were performed for $\mathrm{NaCl}-$ type $\mathrm{UN}, \mathrm{CaF}_{2}$-type $\mathrm{UO}_{2}$, and $\mathrm{Mn}_{2} \mathrm{O}_{3}$-type $\mathrm{U}_{2} \mathrm{~N}_{3}$ with ferromagnetic magnetic ordering, as well as $\mathrm{O}_{2}$ molecule in its ground triplet state. Importantly, the total energy change associated with the oxidation reaction of Eq. (1) is predicted to be $-6.62 \mathrm{eV}$ assuming that $\mathrm{N}$ atoms are in the form of interstitial atoms at tetrahedral sites in UN matrix. Such a negative value indicates that the oxidation of UN is highly favored thermodynamically, and will occur even at very low oxygen partial pressures. The $\mathrm{N}$ interstitial atoms can migrate to the $\mathrm{UN}$ surface and combine into $\mathrm{N}_{2}$ gas molecules, followed by an energy reduction of $1.31 \mathrm{eV}$ per $\mathrm{N}_{2}$ molecule. Alternatively, the $\mathrm{N}$ interstitials can accumulate in the UN matrix and force its phase transformation into $\mathrm{U}_{2} \mathrm{~N}_{3}$ via the reaction of Eq. (2), with a further energy reduction of $2.36 \mathrm{eV}$. The net reaction is therefore $3 \mathrm{UN}$ $+\mathrm{O}_{2}=\mathrm{UO}_{2}+\mathrm{U}_{2} \mathrm{~N}_{3}$ with an energy change of $-8.97 \mathrm{eV}$.

To further predict the interfacial energy between $\mathrm{UO}_{2}$ and $\mathrm{U}_{2} \mathrm{~N}_{3}$, we have constructed a large 256-atom supercell containing $96 \mathrm{U}$ atoms, $96 \mathrm{~N}$ atoms, and $64 \mathrm{O}$ atoms, as shown in Fig. 7. Since

the supercell contains two equivalent $\mathrm{UO}_{2} / \mathrm{U}_{2} \mathrm{~N}_{3}$ interfaces, the interfacial energy, $\sigma$ is calculated as follows: 


$$
\sigma=\frac{E_{\text {supercell }}-32 E_{U O_{2}}-32 E_{U_{2} N_{3}}}{2 A}
$$

where A represents the area of the interface. Our final calculated interfacial energy is $127 \mathrm{~mJ} / \mathrm{m}^{2}$. Such a low value is consistent with our experimental observation of a fully coherent $\mathrm{UO}_{2} / \mathrm{U}_{2} \mathrm{~N}_{3}$ interface. Using our ab initio calculated lattice constants for $\mathrm{UO}_{2}(5.42 \AA)$ and $\mathrm{U}_{2} \mathrm{~N}_{3}(10.66 \AA)$, the lattice misfit of $\mathrm{U}_{2} \mathrm{~N}_{3} / \mathrm{UO}_{2}$ interface was predicted to be $1.7 \%$. Note that, due to such a lattice misfit, our calculated energy for the coherent $\mathrm{U}_{2} \mathrm{~N}_{3} / \mathrm{UO}_{2}$ interface using Eq. (3) also contains contribution from elastic strain energy. While it is possible to separate the contributions due to interfacial energy and strain energy by calculating $\sigma$ using several supercells with increasing sizes, such calculations are computationally demanding and were not performed in the present study.

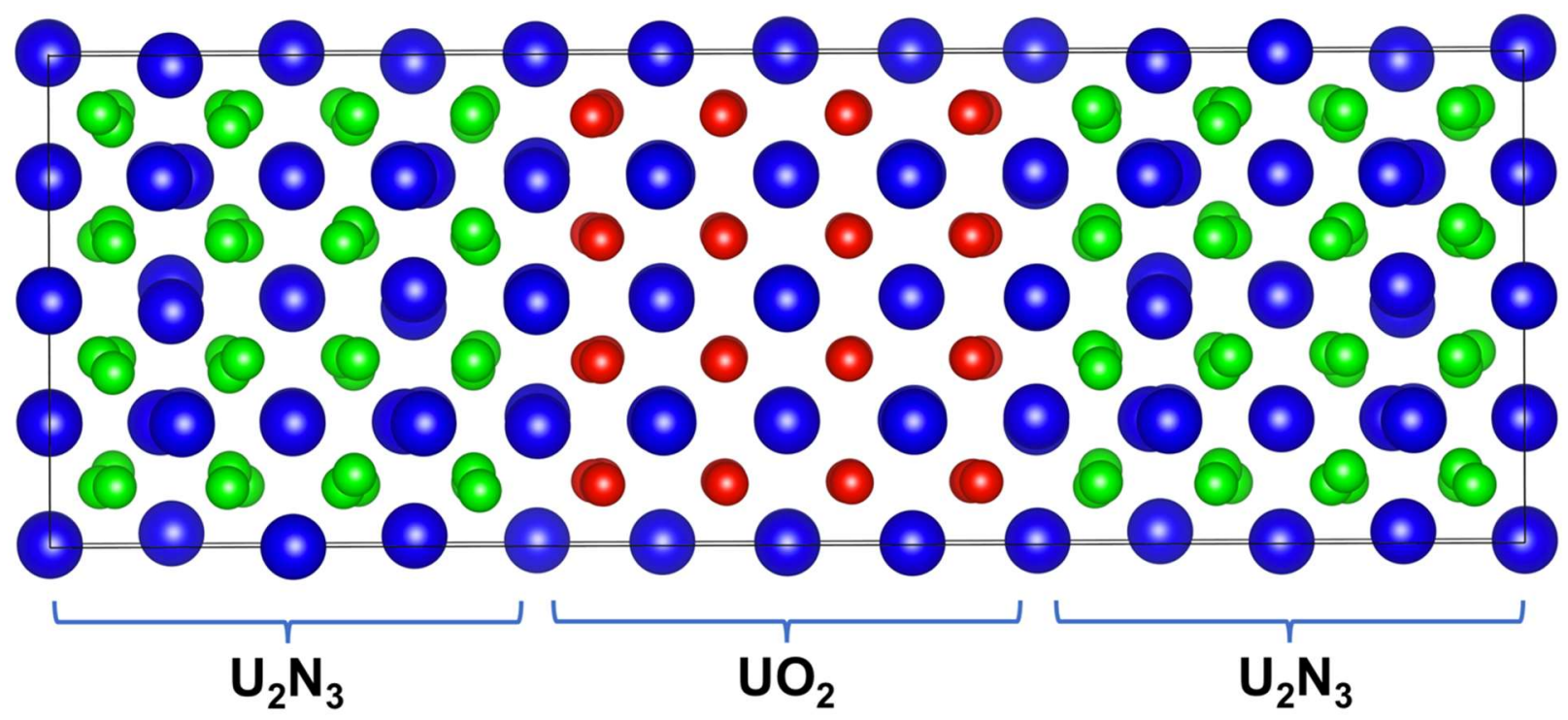

(color online) Figure 7. A periodic supercell used for calculating the interfacial energy for the coherent interface between $\mathrm{UO}_{2}$ and $\mathrm{U}_{2} \mathrm{~N}_{3}$ with the experimentally observed OR. The blue, red, and green spheres represent $\mathrm{U}, \mathrm{O}$, and $\mathrm{N}$ atoms, respectively.

\subsection{Dislocation loop observation}



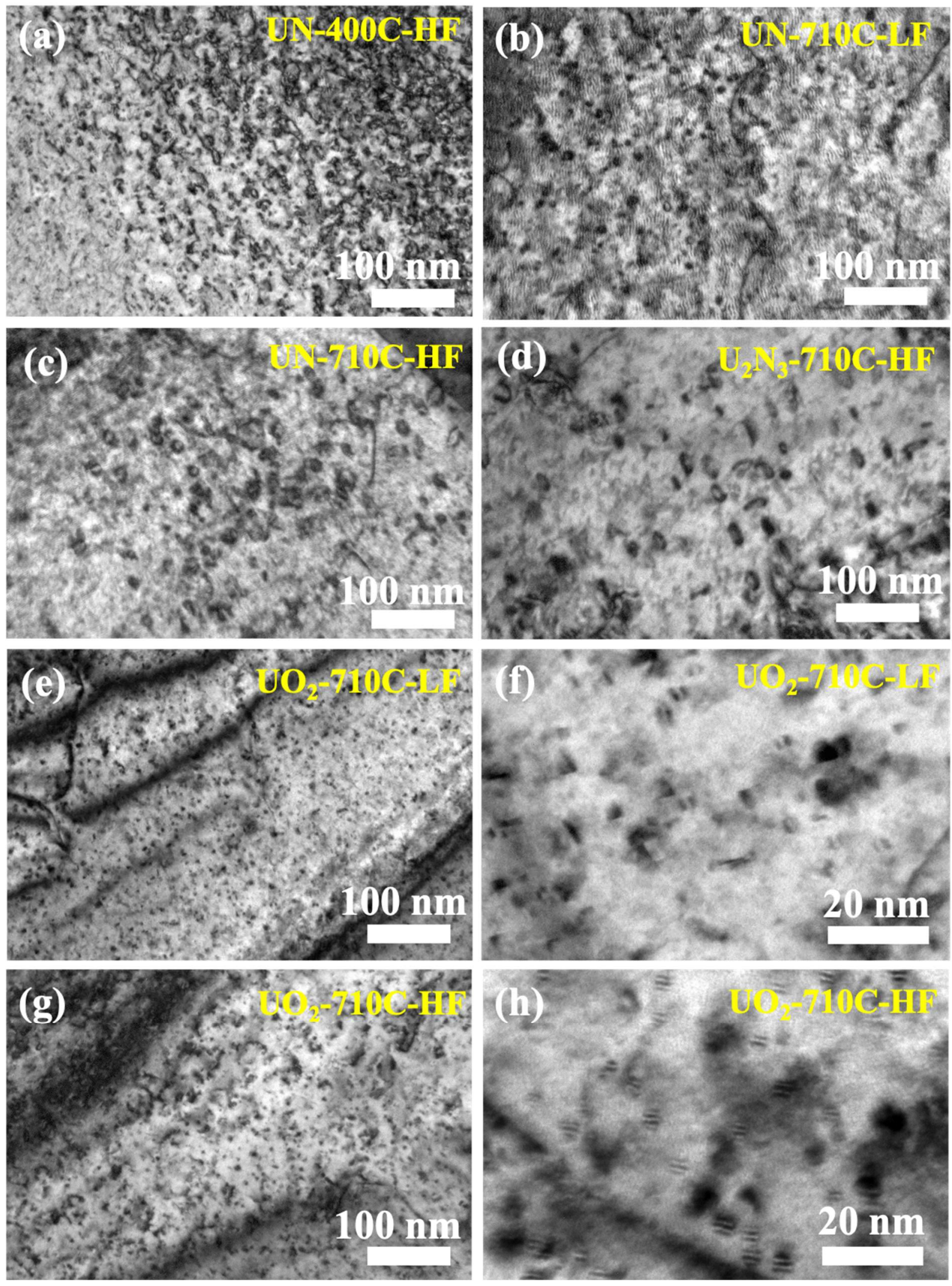
Figure 8. Dislocation loops in (a)-(c) $\mathrm{UN}$, (d) $\mathrm{U}_{2} \mathrm{~N}_{3}$, and (e)-(h) $\mathrm{UO}_{2}$ phases in $\mathrm{UN}-5 \mathrm{UO}_{2}$ composite irradiated under different conditions. (a) $400^{\circ} \mathrm{C}$ and $8 \times 10^{18}$ ions $/ \mathrm{cm}^{2}$ (400C-HF), (b), (e), (f) $710^{\circ} \mathrm{C}$ and $4 \times 10^{18}$ ions $/ \mathrm{cm}^{2}(710 \mathrm{C}-\mathrm{LF}),(\mathrm{c}),(\mathrm{d}),(\mathrm{g}),(\mathrm{h}) 710^{\circ} \mathrm{C}$ and $8 \times 10^{18}$ ions $/ \mathrm{cm}^{2}$ (710C-HF); (f) and (h) are high magnification images of (e) and (g), respectively.
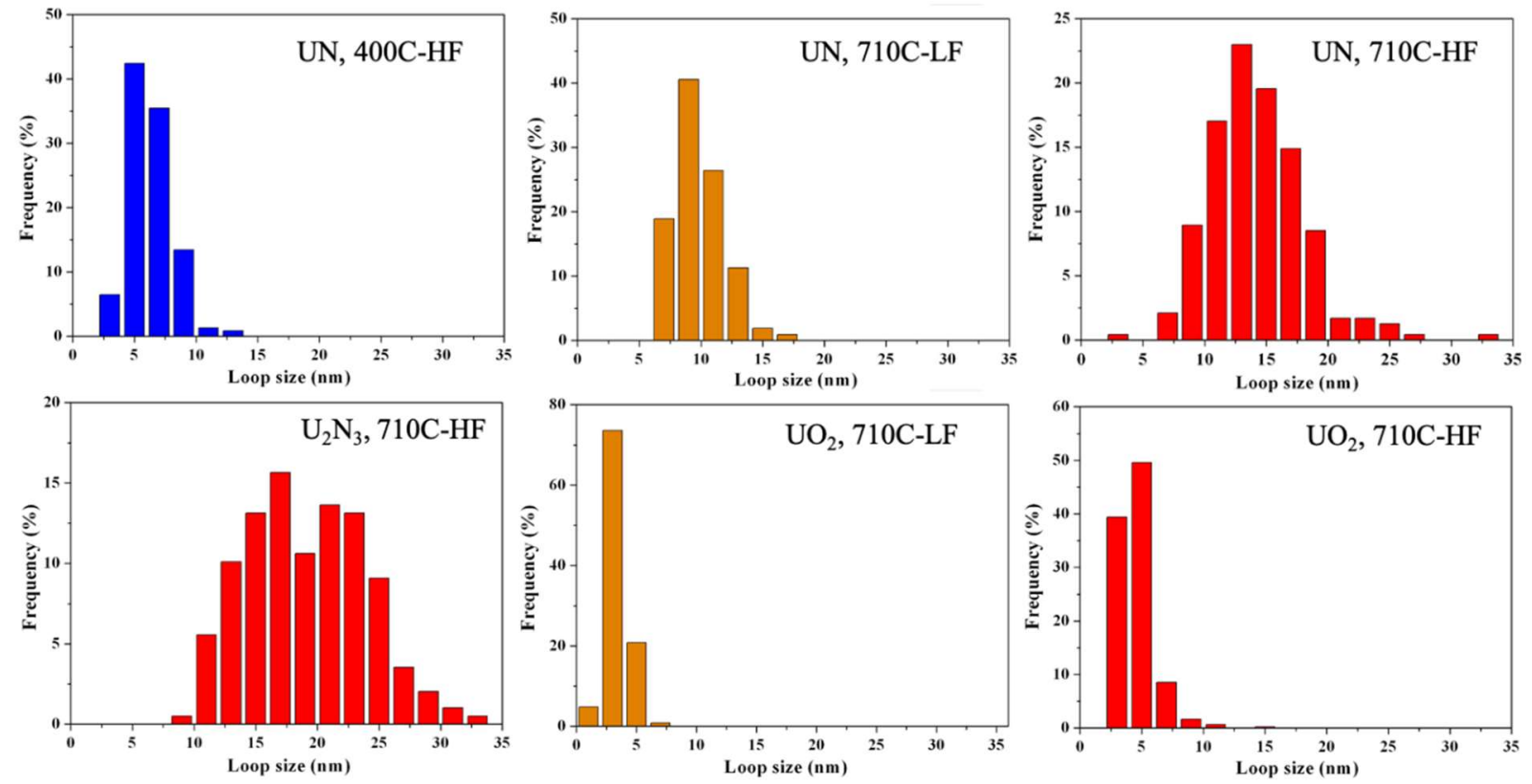

(color online) Figure 9. Dislocation loop size distribution in $\mathrm{UN}, \mathrm{U}_{2} \mathrm{~N}_{3}$, and $\mathrm{UO}_{2}$ phases in the UN-5UO 2 composite irradiated at $400{ }^{\circ} \mathrm{C}$ and $8 \times 10^{18} \mathrm{ions} / \mathrm{cm}^{2}$ (400C-HF) (blue), $710{ }^{\circ} \mathrm{C}$ and $4 \times 10^{18}$ ions $/ \mathrm{cm}^{2}$ (710C-LF) (orange) and $710^{\circ} \mathrm{C}$ and $8 \times 10^{18} \mathrm{ions} / \mathrm{cm}^{2}$ (710C-HF) (red).

Table 2. Dislocation loop size and density in three phases of $\mathrm{UN}-5 \mathrm{UO}_{2}$ composite irradiated with proton at $400{ }^{\circ} \mathrm{C}$ and $710{ }^{\circ} \mathrm{C}$ up to a fluence of $8 \times 10^{18}$ ions $/ \mathrm{cm}^{2}$ (400C-HF, $710 \mathrm{C}-\mathrm{LF}$, and $710 \mathrm{C}-$ HF).

\begin{tabular}{|l|l|l|l|l|l|l|}
\hline & \multicolumn{2}{|l|}{$400 \mathrm{C}-\mathrm{HF}$} & \multicolumn{2}{l|}{$710 \mathrm{C}-\mathrm{LF}$} & \multicolumn{2}{l|}{$710 \mathrm{C}-\mathrm{HF}$} \\
\hline & Size (nm) & $\begin{array}{l}\text { Density } \\
\left(\times 10^{21} \mathrm{~m}^{-3}\right)\end{array}$ & Size (nm) & Density & Size (nm) & Density \\
& & $\left(\times 10^{21} \mathrm{~m}^{-3}\right)$ & & $\left(\times 10^{21} \mathrm{~m}^{-3}\right)$ \\
\hline UN & $6.2 \pm 1.7$ & $13.3 \pm 5.3$ & $9.8 \pm 2.0$ & $2.7 \pm 0.5$ & $14.2 \pm 3.9$ & $2.5 \pm 0.4$ \\
\hline
\end{tabular}




\begin{tabular}{|l|l|l|l|l|l|l|}
\hline $\mathrm{U}_{2} \mathrm{~N}_{3}$ & & & & & $19.0 \pm 4.8$ & $1.9 \pm 0.4$ \\
\hline $\mathrm{UO}_{2}$ & & & $3.3 \pm 0.9$ & $21.0 \pm 6.3$ & $4.5 \pm 1.4$ & $17.0 \pm 1.5$ \\
\hline
\end{tabular}

Figure 8 shows the microstructure of dislocation loops in different phases in $\mathrm{UN}-5 \mathrm{UO}_{2}$ composites after proton irradiation to fluence up to $8 \times 10^{18}$ ions $/ \mathrm{cm}^{2}$ at $400{ }^{\circ} \mathrm{C}$ to fluences up to $4 \times 10^{18}$ and $8 \times 10^{18}$ ions $/ \mathrm{cm}^{2}$ at $710{ }^{\circ} \mathrm{C}$. The size distribution of dislocation loops is shown in Figure 9 and the average loop size and number density are summarized in Table 2. It was surprising to see the formation of dislocation loops in $\mathrm{UN}$ at $400{ }^{\circ} \mathrm{C}(673 \mathrm{~K})$ (Figure $7(\mathrm{a})$ ), which is only $0.22 \mathrm{~T}_{\mathrm{m}}$ of $\mathrm{UN}(3120 \mathrm{~K}$ [68]). The average loop size in $\mathrm{UN}$ is $6.2 \pm 1.7 \mathrm{~nm}$ and the number density is $(13.3 \pm 5.3) \times 10^{21} \mathrm{~m}^{-3}$ for the sample irradiated at $400{ }^{\circ} \mathrm{C}$ up to $8 \times 10^{18}$ ions $/ \mathrm{cm}^{2}$ (corresponding to $0.63 \mathrm{dpa})$. For the $710^{\circ} \mathrm{C}$ irradiation, the average loop size of $\mathrm{UN}$ increased remarkably $(9.8 \pm 2.0$ $\mathrm{nm}$ and $14.2 \pm 3.9 \mathrm{~nm}$ at $4 \times 10^{18}$ and $8 \times 10^{18}$ ions $/ \mathrm{cm}^{2}$, respectively) while the number density decreased significantly $\left((2.7 \pm 0.5) \times 10^{21}\right.$ and $(2.5 \pm 0.4) \times 10^{21} \mathrm{~m}^{-3}$ at fluences of $4 \times 10^{18}$ and $8 \times 10^{18}$ ions $/ \mathrm{cm}^{2}$, respectively). The dislocation loops in $\mathrm{UO}_{2}$ were extremely small and manifest as black dots at low magnification (Figure 8(e) and 8(g)). A coffee-bean shape (Figure 8(f) and 8(h)) contrast arose when these small dislocation loops were imaged at high magnification. Similar to $\mathrm{UN}$, the average loop size in $\mathrm{UO}_{2}$ also increased with the dose from $3.3 \pm 0.9 \mathrm{~nm}$ at the fluence of $4 \times 10^{18}$ ions $/ \mathrm{cm}^{2}(0.27 \mathrm{dpa})$ to $4.5 \pm 1.4 \mathrm{~nm}$ at the fluence of $8 \times 10^{18}$ ions $/ \mathrm{cm}^{2}$ (corresponding to 0.55 dpa), while the loop number density decreased slightly (from $(21.0 \pm 6.3) \times 10^{21} \mathrm{~m}^{-3}$ at 0.27 dpa to $(17.0 \pm 1.5) \times 10^{21} \mathrm{~m}^{-3}$ at $\left.0.55 \mathrm{dpa}\right)$. The number density of loops in $\mathrm{UO}_{2}$ is about one order of magnitude higher than that in $\mathrm{UN}$ and $\mathrm{U}_{2} \mathrm{~N}_{3}$, while the average loop size and loop size distribution in $\mathrm{UO}_{2}$ is much smaller and narrower, respectively than those in $\mathrm{UN}$ and $\mathrm{U}_{2} \mathrm{~N}_{3}$, under the same irradiation conditions. For example, the measured average loop sizes in $\mathrm{UN}, \mathrm{U}_{2} \mathrm{~N}_{3}$ and $\mathrm{UO}_{2}$ were 
14.2 $\pm 3.9 \mathrm{~nm}, 19.0 \pm 4.8 \mathrm{~nm}$ and $4.5 \pm 1.4 \mathrm{~nm}$, respectively, and the loop densities were $(2.5 \pm 0.4) \times 10^{21} \mathrm{~m}^{-3},(1.9 \pm 0.4) \times 10^{21} \mathrm{~m}^{-3}$, and $(17.0 \pm 1.5) \times 10^{21} \mathrm{~m}^{-3}$, respectively at $710{ }^{\circ} \mathrm{C}$ and $8 \times 10^{18}$ ions $/ \mathrm{cm}^{2}$. Assuming all the dislocation loops were formed from the clustering of interstitials into the disk-shaped platelets, the density of interstitials in the loops could be estimated from loop area per unit volume, $S$ [69]. The calculated $S$ for $\mathrm{UN}, \mathrm{U}_{2} \mathrm{~N}_{3}$ and $\mathrm{UO}_{2}$ were $4.0 \times 10^{5} \mathrm{~m}^{-1}, 5.4 \times 10^{5} \mathrm{~m}^{-1}$, and $2.7 \times 10^{5} \mathrm{~m}^{-1}$, respectively under the irradiation at $710{ }^{\circ} \mathrm{C}$ and $8 \times 10^{18}$ ions $/ \mathrm{cm}^{2}$. Based on the loop size and loop area per volume, it is concluded that the resistance to irradiation induced loop growth of three phases in $\mathrm{UN}-\mathrm{UO}_{2}$ composites follow the sequence of $\mathrm{UO}_{2}>\mathrm{UN}>\mathrm{U}_{2} \mathrm{~N}_{3}$. We attribute this to difference in the mobility of interstitials and this mechanism will be discussed in section 4.2 .

\section{Discussion}

\subsection{Phase evolution}

The as-sintered $\mathrm{UN}-5 \mathrm{UO}_{2}$ composite contains a minor amount of $\mathrm{U}_{2} \mathrm{~N}_{3}$ phase because even low levels of oxygen impurity $(<1 \mathrm{wt} . \%)$ can stabilize $\mathrm{U}_{2} \mathrm{~N}_{3}$ phase at higher temperatures [70]. Oxidation of UN powders starts at $200^{\circ} \mathrm{C}$ by a slow absorption of oxygen, leading to formation of weakly crystallized $\mathrm{U}_{2} \mathrm{~N}_{3}$ and $\mathrm{UO}_{2}$, and becomes more intensive at $250{ }^{\circ} \mathrm{C}$ accompanied by a decrease of $\mathrm{U}_{2} \mathrm{~N}_{3}$ and appearance of $\alpha-\mathrm{UO}_{3}$ phase [54]. During the early stage of isothermal oxidation of $\mathrm{UN}$ powers at $260{ }^{\circ} \mathrm{C}$, coexistence of $\mathrm{UN}, \mathrm{U}_{2} \mathrm{~N}_{3}, \mathrm{UO}_{2}$ has been observed [52]. The $\mathrm{UN}-5 \mathrm{UO}_{2}$ composite exhibits similar oxidation products during the early-stage oxidation of UN powers. More complicated phase evolution was observed during oxidation of UN single crystal. In the early stages of oxidation at $280{ }^{\circ} \mathrm{C}$, the only phase identified by XRD was $\mathrm{U}_{2} \mathrm{~N}_{3+\mathrm{x}}$, which was assumed to be a mixed oxynitride $\left(\mathrm{U}_{2} \mathrm{~N}_{3+\mathrm{x}} \mathrm{O}_{\mathrm{y}}[51]\right)$. At temperatures $>400{ }^{\circ} \mathrm{C}$, a $\mathrm{UN} / \mathrm{U}_{2} \mathrm{~N}_{3} / \mathrm{UO}_{2}$ 
sandwich structure formed with both the $\mathrm{U}_{2} \mathrm{~N}_{3}$ and $\mathrm{UO}_{2}$ layers being epitaxially oriented with respect to the $\mathrm{UN}$ crystal [53]. Although the general phase distribution in $\mathrm{UN}-5 \mathrm{UO}_{2}$ composite is different compared to the UN crystal, the sandwich structure was still observed at local regions.

The crystal structures of $\mathrm{UN}, \mathrm{U}_{2} \mathrm{~N}_{3}$ and $\mathrm{UO}_{2}$ are all based on a fcc array of uranium atoms [52]. There is a significant lattice expansion during transformation of $\mathrm{UN}$ to $\mathrm{U}_{2} \mathrm{~N}_{3}(9.3 \%)$ and from $\mathrm{UN}$ to $\mathrm{UO}_{2}(11.9 \%)$, while only small expansion occurs $\mathrm{U}_{2} \mathrm{~N}_{3}$ to $\mathrm{UO}_{2}$ transformation (2.4\%). The small lattice misfit between $\mathrm{U}_{2} \mathrm{~N}_{3}$ and $\mathrm{UO}_{2}$ is also in excellent agreement with those calculated from our DFT. $\mathrm{U}_{2} \mathrm{~N}_{3}$ can act as buffer layer between $\mathrm{UN}$ and $\mathrm{UO}_{2}\left(\mathrm{UN} / \mathrm{U}_{2} \mathrm{~N}_{3} / \mathrm{UO}_{2}\right.$ sandwich structure) to reduce lattice misfit. The small lattice misfit and small interfacial energy of $\mathrm{U}_{2} \mathrm{~N}_{3} / \mathrm{UO}_{2}$ facilitates the formation of coherent structure between $\mathrm{U}_{2} \mathrm{~N}_{3}$ and $\mathrm{UO}_{2}$ phases. Although there is a large lattice misfit between $\mathrm{UO}_{2}$ and $\mathrm{UN}$, the two phases still maintain a $\mathrm{OR}$ of [101]UN\|[101] $\mathrm{UO}_{2}$ and (111) $\mathrm{UN} \|(111) \mathrm{UO}_{2}$. This $\mathrm{OR}$ combined with full coherence between $\mathrm{UO}_{2}$ and $\mathrm{U}_{2} \mathrm{~N}_{3}$ may indicate that the fcc array of $\mathrm{U}$ atoms is maintained during oxidation. In other words, when the solid phase reaction occurred at $\mathrm{UN} / \mathrm{UO}_{2}$ and $\mathrm{UN} / \mathrm{U}_{2} \mathrm{~N}_{3}$ interfaces, $\mathrm{N}$ and $\mathrm{O}$ atoms were transported by lattice diffusion [47]. The sawtooth-like morphology between $\mathrm{UO}_{2}$ and $\mathrm{UN}$ is very similar to the morphology of boride layer on low-carbon steels induced by a diffusion process [70]. However, the formation mechanism is still unclear and heterogeneous surface microstructure could be a main cause [70].

The Pilling-Bedworth ratio (PBR) can be estimated according to the relationship, PBR = $\mathrm{M}_{\mathrm{UO} 2} \rho_{\mathrm{UN}} /\left(\mathrm{M}_{\mathrm{UN}} \rho_{\mathrm{UO} 2}\right)$, where $\mathrm{M}_{\mathrm{UO2}}(270 \mathrm{~g} / \mathrm{mol})$ and $\rho_{\mathrm{UO} 2}\left(10.97 \mathrm{~g} / \mathrm{cm}^{3}\right)$ are the molecular weight and density of oxide scales, respectively, and $\mathrm{M}_{\mathrm{UN}}(252 \mathrm{~g} / \mathrm{mol})$ and $\rho_{\mathrm{UN}}\left(14.32 \mathrm{~g} / \mathrm{cm}^{3}\right)$ are the molecular weight and density of $\mathrm{UN}$, respectively. The PBR value of $\mathrm{UN} / \mathrm{UO}_{2}$ is 1.4. Similarly, 
the PBR value of $\mathrm{UN} / \mathrm{U}_{2} \mathrm{~N}_{3}$ is calculated to be 1.3 . These PBR values imply that a compressive stress should exist in $\mathrm{UO}_{2}$ and $\mathrm{U}_{2} \mathrm{~N}_{3}$ (a tensile stress in $\mathrm{UN}$ ) as a result of $\mathrm{UO}_{2}$ and $\mathrm{U}_{2} \mathrm{~N}_{3}$ growth.

In the $\mathrm{UN}-\mathrm{UO}_{2}$ composite, $\mathrm{UN}$ phase near the surface experienced oxidation leading to formation of both $\mathrm{UO}_{2}$ and $\mathrm{U}_{2} \mathrm{~N}_{3}$. Some oxidation was also evident underneath the residual $\mathrm{UN}$ phase (Figure 3), indicating that oxygen potential may not exhibit a perfect gradient from the surface to the center of bulk. The oxygen diffusion in the bulk of composite through grain boundaries and/or other defects (e.g. pores) may play an important role in the oxidation process. $\mathrm{U}_{2} \mathrm{~N}_{3}$ showed better oxidation resistance than $\mathrm{UN}$ and can survive at high oxygen potential regions near the surface. Moiré fringes readily formed in $\mathrm{UN}$ (Figure 8b) rather than in $\mathrm{U}_{2} \mathrm{~N}_{3}$ and these fringes are due to the formation of surface oxides. $\mathrm{U}_{2} \mathrm{~N}_{3}$ coating or thin film has been demonstrated to protect uranium metal from oxidation and corrosion [47].

According to the literature and DFT calculation, the two main oxidation reactions for $\mathrm{UN}$ are $\mathrm{UN}(\mathrm{s})+\mathrm{O}_{2}(\mathrm{~g})=\mathrm{UO}_{2}(\mathrm{~s})+1 / 2 \mathrm{~N}_{2}(\mathrm{~g})$ and $\mathrm{UN}(\mathrm{s})+1 / 3 \mathrm{O}_{2}(\mathrm{~g})=1 / 3 \mathrm{U}_{2} \mathrm{~N}_{3}(\mathrm{~s})+1 / 3 \mathrm{UO}_{2}(\mathrm{~s})$. There is $\mathrm{N}_{2}$ gas release in the first reaction but not in the second reaction. It would be of significance to know which reaction would dominate the oxidation of UN under various irradiation conditions. Assuming only the volume measured by XRD experienced oxidation and based on the phase evolution measured by XRD, we calculated the fraction of UN that experienced oxidation via these two reactions under different irradiation conditions (Tables $\mathrm{S} 2$ and $\mathrm{S} 3$ in SI). At $400{ }^{\circ} \mathrm{C}$, about $20 \% \mathrm{UN}$ experienced oxidation via the first reaction with $\mathrm{N}_{2}$ gas release. The fraction of $\mathrm{UN}$ experiencing the first reaction increases with fluence and temperature. At $710{ }^{\circ} \mathrm{C}$, roughly $40 \%$ and $75 \%$ UN experienced oxidation at low and high fluences, respectively via the first reaction. However, $\mathrm{U}_{2} \mathrm{~N}_{3}$ and $\mathrm{UO}_{2}$ also exist well below the surface, beyond the XRD measurement depth. 
Therefore, the above calculation of UN oxidation should not be over-interpreted and a better designed experiment is needed in the future to confirm this analysis.

Electron irradiation has been reported to activate oxidation of metals and compounds [4, 72-74]. Electron beam in TEM has two effects: knock-on damage and radiolysis. On the one hand, electron beam could induce the migration of atoms [4]. On the other hand, electron could ionize molecular oxygen to form atomic oxygen, which may promote the oxidation. Similar to electron irradiation, $2 \mathrm{MeV}$ proton irradiation investigated in this study may have played an important role in assisting the oxidation of UN $[75,76]$. The displacement induced by proton irradiation may have increased defect concentrations and enhanced mass transport, leading to accelerated oxidation. The proton irradiations in this study were conducted at a base pressure of $<10^{-4} \mathrm{~Pa}$, as a result some residual oxygen may be present in the irradiation chamber [77], which could oxidize the UN during proton irradiation. Radiation-enhanced oxidation in the accelerators at both room temperature and elevated temperatures, even in superior vacuum (on the order of $10^{-5}-10^{-6} \mathrm{~Pa}$ ) has been observed in $\mathrm{ZrC}[6,7,78,79]$. Nanosized $\mathrm{ZrO}_{2}$ precipitates or nodules were observed to grow over the surface of $\mathrm{ZrC}_{\mathrm{x}}$ after irradiation with $\mathrm{MeV} \mathrm{Au}{ }^{3+}$ ions at either room temperature or $800^{\circ} \mathrm{C}[6,7]$. 


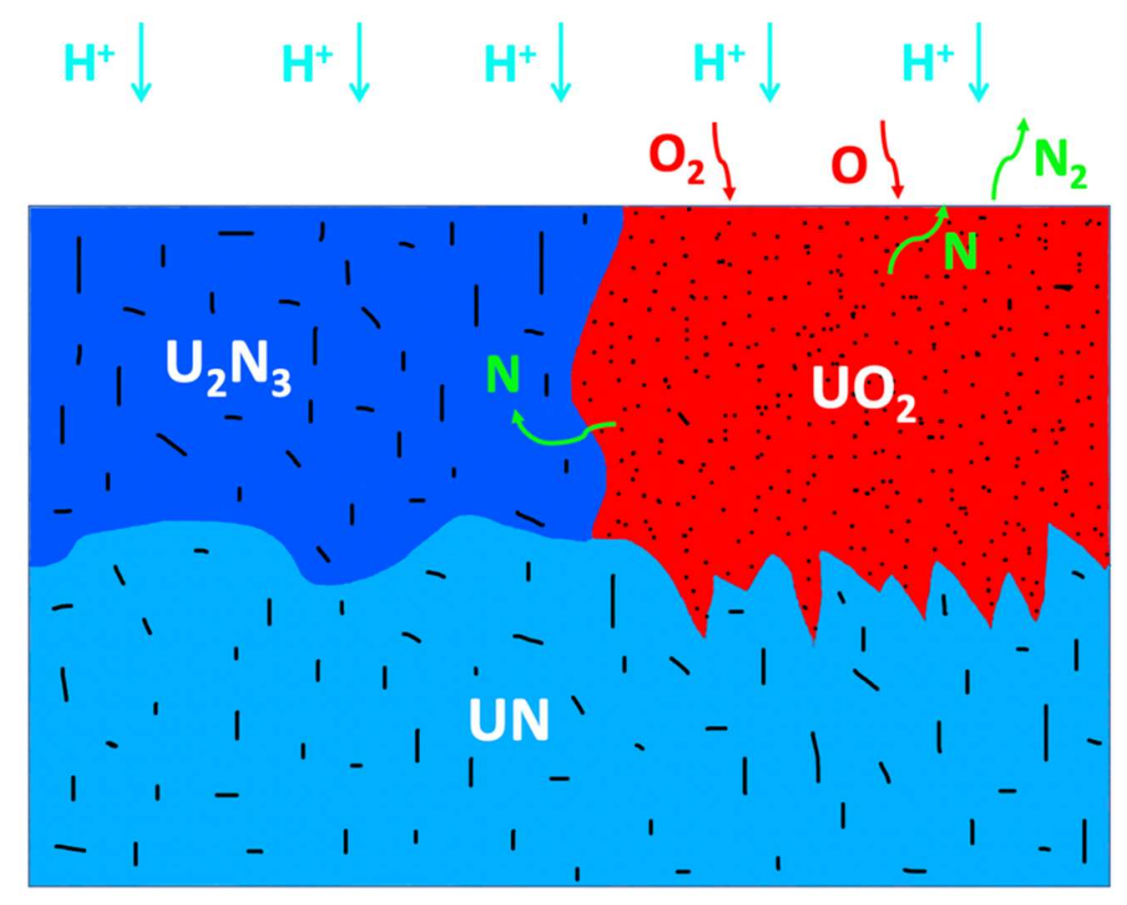

Figure 10. Illustration of the phase and defect evolution in U-N-O system under proton irradiation.

The microstructural evolution of UN under irradiation can be illustrated in Figure 10. Molecular $\mathrm{O}_{2}$ and irradiation induced atomic $\mathrm{O}$ atom attacked the $\mathrm{UN}$ and formed $\mathrm{UO}_{2}$ phase and $\mathrm{N}$ interstitial atoms. $\mathrm{N}$ interstitials may either escape to the sample surface and form molecular $\mathrm{N}_{2}$ gas or react with $\mathrm{UN}$ to form $\mathrm{U}_{2} \mathrm{~N}_{3}$ phase. To reveal the detailed oxidation mechanism of $\mathrm{UN}$, in situ heating studies will be pursued in the near future to reveal the phase evolution during annealing. The evolution of dislocation loops (black dashes or dots in Figure 10) will be discussed in 4.2.

\subsection{Defect evolution}

At $400{ }^{\circ} \mathrm{C}$, no extended defects were observed in $\mathrm{UO}_{2}$, indicating that the principal irradiation induced defects are point defects and/or their clusters with size below the resolution limit of TEM. Extended defects, (i.e. dislocation loops) were observed in UN under the same irradiation 
conditions as $\mathrm{UO}_{2}$ and the point defects in $\mathrm{UN}$ may also exist and more mobile than those in $\mathrm{UO}_{2}$. For the $710{ }^{\circ} \mathrm{C}$ irradiation, the dislocation loops in $\mathrm{UN}$ and $\mathrm{UO}_{2}$ were well developed.

Analysis of the microstructural evolution using kinetic rate equations provides further insight into mechanism of loop evolution. Rate equations are written in general form for compound $X_{x} Y_{y}$, They describe evolution of v-vacancies and i-interstitial for each element $\mathrm{K}$ in the compound and stoichiometric loops. The model considers generation of defects due to displacement, mutual recombination of i-v pairs, and clustering of interstitials into a stoichiometric interstitial loops and is given by $[80,81]$ :

$$
\begin{aligned}
\frac{d C_{v K}}{d t}=G_{v K}- & \frac{\Omega_{0}}{a^{2}}\left(Z_{i K}^{i v} D_{i K}+Z_{v K}^{i v} D_{v K}\right) C_{i K} C_{v K}-k \cdot \pi r_{0} j_{v}^{L} \cdot 2 \pi N_{L} R_{L} \\
\frac{d C_{i K}}{d t}=G_{i K}- & \frac{\Omega_{0}}{a^{2}}\left(Z_{i K}^{i v} D_{i K}+Z_{v K}^{i v} D_{v K}\right) C_{i K} C_{v K}-k \cdot \pi r_{0} j_{i}^{L} \cdot 2 \pi N_{L} R_{L} \\
& -k \frac{\Omega_{0}}{a^{2}} Z_{i K}^{i i} j_{i i}
\end{aligned}
$$

$C$ is monomer concentration, $G$ is their production rate, obtained from SRIM calculation, $Z_{i}^{i v}$ and $Z_{v}^{i v}$ are the number of spontaneous recombination sites of interstitial-vacancy pair for mobile interstitials and vacancies, respectively, $Z_{i}^{i i}$ is the number of site for di-interstitial clustering, $D$ is diffusion coefficient of individual monomers, $N_{L}$ and $R_{L}$ are loop density and radius, respectively. $K$ is used to denote $\mathrm{U}$ and either $\mathrm{O}$ or $\mathrm{N}$, and $k$ is stoichiometry of $K$. When both atoms need to be distinguished a combination of $(\mathrm{X}, \mathrm{x})$ and $(\mathrm{Y}, \mathrm{y})$ are used for metal and non-metal ion, respectively, to represent compound $\mathrm{X}_{\mathrm{x}} \mathrm{Y}_{\mathrm{y}}, \Omega_{0}$ is atomic density, and $a$ is lattice constant. The first term represents the production of vacancies and interstitials, the second term captures mutual recombination of interstitials and vacancies of the same type, the third term represents absorption at dislocation loops, and the last term, present only in the interstitial rate equation, describes the 
loop nucleation. In principle, the last term in Eq. (4) can be neglected since uranium vacancies have very low mobility over the temperature range of interest.

Defect fluxes at the loop surface that satisfy the stoichiometric evolution of the loop are given by [82]

$$
\begin{aligned}
& j_{i}^{L}=\frac{1}{r_{0} \ln \left(\frac{8 R_{L}}{r_{0}}\right)} \times \frac{D_{i X} C_{i X} D_{i Y} C_{i Y}}{y D_{i X} C_{i X}+x D_{i Y} C_{i Y}} \\
& j_{v}^{L}=\frac{1}{r_{0} \ln \left(\frac{8 R_{L}}{r_{0}}\right)} \times \frac{D_{v X} C_{v X} D_{v Y} C_{v Y}}{y D_{v X} C_{v X}+x D_{v Y} C_{v Y}}
\end{aligned}
$$

Eqs. (6) and (7) assume a toroidal shape with radius of revolution equal to loop diameter $R_{\mathrm{L}}$ and its cross-sectional radius $r_{0}$, where $r_{0}=4 a$ is the effective capture radius about the circumference of the loop. Loop nucleation is controlled by the formation of di-interstitial of the slowest species and is governed by an effective flux, as follows,

$$
j_{i i}=\frac{D_{i X} C_{i X}^{2} D_{i Y} C_{i Y}^{2}}{y D_{i X} C_{i X}^{2}+x D_{i Y} C_{i Y}^{2}}
$$

Loop evolution is described by loop nucleation and its radial growth [83]:

$$
\begin{aligned}
& \frac{d N_{L}}{d t}=\frac{1}{k} \frac{\Omega_{0}}{a^{2}} Z_{i k}^{i i} j_{i i} \\
& \frac{d R_{L}}{d t}=(x+y) \Omega \frac{2 \pi r_{0}}{b}\left(j_{i}^{L}-j_{v}^{L}\right)-\frac{R_{L}}{2 N_{L}} \frac{d N_{L}}{d t}
\end{aligned}
$$

In this model special treatment is needed for loop growth described by Eq. (10). Initially loop growth rate is negative which is not physical. The solution to this unphysical condition is addressed by requiring defect fluxes defined by Eqs. (8) and (9) to be zero if both Eq. (10) is negative and loop size has not substantially increased from a minimum size defined by a diameter of a 
stoichiometric interstitial cluster containing two uranium interstitials. Loop growth is controlled by the species with the lowest particle flux [85]. Combinatorial numbers for recombination rate and loop nucleation are determined using procedures outlined by Olander assuming selfinterstitials occupy octahedral interstitial sites in fluorite $\mathrm{UO}_{2}$, tetrahedral site in rock-salt $\mathrm{UN}$, and unoccupied tetrahedral sites of $\mathrm{U}_{2} \mathrm{~N}_{3}$ 's $\mathrm{Mn}_{2} \mathrm{O}_{3}$ type structure [84].

While loop growth is primarily determined by interstitial mobility, non-metal vacancies still play an indirect role. In this analysis non-metal vacancy diffusion impacts nucleation rate for interstitials as it controls quasi-equilibrium concentration of interstitials through recombination.

Table 3. Parameters used for kinetic rate equation modeling

\begin{tabular}{|c|c|c|c|c|c|c|c|c|}
\hline & $\begin{array}{l}\text { Crystal } \\
\text { structure }\end{array}$ & $\begin{array}{l}\text { Lattice } \\
\text { Constant } \\
(\mathrm{nm})\end{array}$ & $\begin{array}{l}\text { Interstitial } \\
\text { site }\end{array}$ & $\begin{array}{l}\text { Metal } \\
\text { production } \\
\text { rate } \\
\left(1 \times 10^{-6}\right. \\
\mathrm{dpa} / \mathrm{s})\end{array}$ & $\begin{array}{l}\text { Nonmetal } \\
\text { production } \\
\text { rate } \\
\left(1 \times 10^{-6}\right. \\
\mathrm{dpa} / \mathrm{s})\end{array}$ & $\begin{array}{l}Z_{i X}^{i v} \\
\text { (metal) }\end{array}$ & $\begin{array}{l}Z_{v Y}^{i v} \\
\text { (non- } \\
\text { metal) }\end{array}$ & $Z_{K}^{i i}$ \\
\hline $\mathrm{UO}_{2}$ & $\begin{array}{l}\text { Fluorite: } \\
\text { U-fcc, O- } \\
\text { tetrahedral }\end{array}$ & 0.547 & $\begin{array}{l}\text { Octahedral } \\
\text { of U-fcc }\end{array}$ & $\sim 2.07$ & $\sim 3.07$ & 48,36 & 36,24 & 84 \\
\hline UN & $\begin{array}{l}\text { Rock-Salt: } \\
\text { U-fcc, N- } \\
\text { octahedral } \\
\text { sites }\end{array}$ & 0.489 & $\begin{array}{l}\text { Tetrahedral } \\
\text { of U-fcc }\end{array}$ & 4.17 & 1.75 & 24,36 & 24,36 & 30 \\
\hline
\end{tabular}




\begin{tabular}{|c|c|c|c|c|c|c|c|c|}
\hline $\mathrm{U}_{2} \mathrm{~N}_{3}$ & $\begin{array}{l}\mathrm{Mn}_{2} \mathrm{O}_{3}- \\
\text { bcc: } \mathrm{U} 1- \\
\text { bcc, U2- } \\
\text { octahedral, } \\
\mathrm{N}-3 / 4 \text { of } \\
\text { tetrahedral }\end{array}$ & 1.0667 & $\begin{array}{l}\text { Remaining } \\
\text { tetrahedral of } \\
\text { U-fcc }\end{array}$ & $\sim 2.77$ & $\sim 1.86$ & 4,24 & 4,36 & 2 \\
\hline $\begin{array}{l}\text { UN- } \\
\text { low }\end{array}$ & & & & 2.89 & 1.21 & & & \\
\hline
\end{tabular}
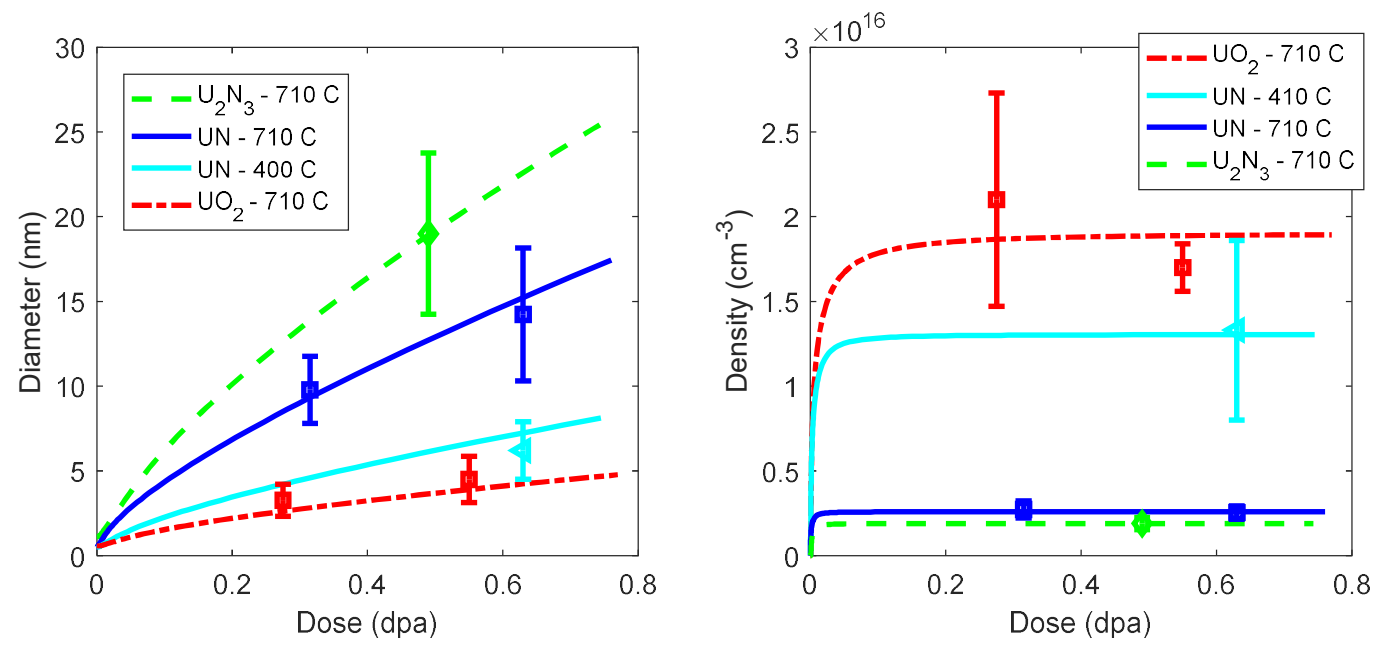

(color online) Figure 11. Kinetic rate equation analysis. (a) loop diameter and (b) density evolution.

Fitting of the experimental data was performed using diffusivities of $U_{I}, Y_{I}$ and $V_{Y}$ as fitting parameters. Results of this analysis are summarized in Fig. 11, which compares model and experimental loop density and size. Concentrations of individual defects as a function of dose are plotted in Figs. S8 and S9 in SI. It was found that mobility of $\mathrm{V}_{\mathrm{U}}$ was too small to impact the evolution and also a reason for not including voids in this analysis. Fitting parameters are 
summarized in Table 4. Since these diffusion coefficients span multiple orders of magnitude, it is much more instructive to compare the effective activation energy $E_{m}^{*}$ that we define using $D=$ $D_{0} e^{-E_{m}^{*} / k_{B} T}$ and $D_{0}=0.01 \mathrm{~cm}^{2} / \mathrm{s}$. This is an attempt to capture Arrhenius type description with data for a single temperature. We also found this approach more suitable for representing the error bars for the fitted diffusivity values based on kinetic rate equation analysis. The effective activation energies should be comparable to actual migration barrier, at least in the case of $\mathrm{UO}_{2}$, as $D_{0}$ is comparable to values reported in the literature [85-87].

Table 4. Diffusivity coefficient and effective activation energy for defects at $710{ }^{\circ} \mathrm{C}$ for $\mathrm{UO}_{2}$, $\mathrm{UN}$ and $\mathrm{U}_{2} \mathrm{~N}_{3}$ and also at $400{ }^{\circ} \mathrm{C}$ for $\mathrm{UN}$. (Y represents either $\mathrm{O}$ or $\mathrm{N}$ )

\begin{tabular}{|l|l|l|l|l|l|l|l|}
\hline Material & Metal & $\begin{array}{l}D_{U_{I}} \\
\left(\mathrm{~cm}^{2} / \mathrm{s}\right)\end{array}$ & $\begin{array}{l}D_{Y_{I}} \\
\left(\mathrm{~cm}^{2} / \mathrm{s}\right)\end{array}$ & $\begin{array}{l}D_{V_{X}} \\
\left(\mathrm{~cm}^{2} / \mathrm{s}\right)\end{array}$ & $\begin{array}{l}E_{m}^{U_{I}} \\
(\mathrm{eV})\end{array}$ & $\begin{array}{l}E_{m}^{Y_{I}} \\
(\mathrm{eV})\end{array}$ & $\begin{array}{l}E_{m}^{V_{Y}} \\
(\mathrm{eV})\end{array}$ \\
\hline $\mathrm{UO}_{2}$ & Very small & $3.1 \times 10^{-19}$ & $6.6 \times 10^{-8}$ & $1.10 \times 10^{-6}$ & $3.2 \pm 0.3$ & $1.0 \pm 0.2$ & $0.7 \pm 0.2$ \\
\hline $\mathrm{UN}-400 \mathrm{C}$ & Very small & $8.7 \times 10^{-19}$ & $3.1 \times 10^{-5}$ & $8.7 \times 10^{-8}$ & $3.1 \pm 0.6$ & $0.5 \pm 0.5$ & $1.0 \pm 0.5$ \\
\hline $\mathrm{UN}$ & Very small & $7.9 \times 10^{-18}$ & $1.1 \times 10^{-3}$ & $5.4 \times 10^{-8}$ & $2.9 \pm 0.2$ & $0.2 \pm 0.1$ & $1.0 \pm 0.2$ \\
\hline $\mathrm{U}_{2} \mathrm{~N}_{3}$ & Very small & $3.3 \times 10^{-18}$ & $1.1 \times 10^{-4}$ & $1.9 \times 10^{-8}$ & $3.0 \pm 0.1$ & $0.4 \pm 0.1$ & $1.1 \pm 0.1$ \\
\hline
\end{tabular}

This set of parameters suggests that both loop nucleation and loop growth are governed by mobility of uranium interstitials. This analysis supports qualitative expectation, that defects responsible for loop evolution are more mobile in two nitrides than the oxide (e.g. $D_{U_{I}}$ is one order of magnitude higher in $\mathrm{U}_{2} \mathrm{~N}_{3}$ and $\mathrm{UN}$ than $\mathrm{UO}_{2}$ at $710{ }^{\circ} \mathrm{C}$ ). Notably, the diffusivity coefficient of nitrogen interstitial atoms are 3 to 4 orders of magnitude higher than oxygen interstitial atoms, and in principle consistent with the fact that nitrides are able to accommodate excess nitrogen much 
easier. Another interesting observation is that interstitials in $\mathrm{U}_{2} \mathrm{~N}_{3}$ are one order of magnitude less mobile than in UN owing to a large number of interstitial sites in UN. Despite lower mobility, loop growth in $\mathrm{U}_{2} \mathrm{~N}_{3}$ is faster due to lower number of recombination sites for Frenkel pair mutual recombination.

Despite the fact that the rate model provides a reasonable description for experimentally observed loop statistics, certain limitations of the model should be discussed. Defect evolution analysis using the rate model for $\mathrm{UO}_{2}$ and $\mathrm{U}_{2} \mathrm{~N}_{3}$ is based on the assumption that the three phases exist before the irradiation. The phase change under irradiation should affect the defect evolution and vice versa and their relationships will be further investigated in the future. Only single mechanism governed by di-interstitial formation for loop nucleation was considered, which results in a saturation of loop density at low doses. However, other loop nucleation and destruction mechanisms could be at play. One of them includes in-cascade formation of loops that results in continued increase of loop density, which has been reported in proton irradiated $\mathrm{ThO}_{2}$ [88]. Another possibility is that loops undergo unfaulting and/or loop merging, which results in decrease in loop density and has been previously reported especially when materials are subject to higher irradiation doses [89-90]. Nevertheless, the error bars for loop density estimation prevent us from concluding if any of these mechanisms are active in current work.

\section{Conclusions}

Proton-irradiation of the $\mathrm{UN}-5 \mathrm{wt} \% \mathrm{UO}_{2}$ composite at 400 and $710{ }^{\circ} \mathrm{C}$ promotes the formation of $\mathrm{U}_{2} \mathrm{~N}_{3}$ and $\mathrm{UO}_{2}$ phases. Oxidation products, $\mathrm{U}_{2} \mathrm{~N}_{3}$ and $\mathrm{UO}_{2}$ phases do not have discernible phase boundaries and instead form full coherent structure with the crystallographic relationship

$\left(\{002\} \mathrm{U}_{2} \mathrm{~N}_{3} \|\{002\} \mathrm{UO}_{2} \quad\right.$ and $\quad[001] \mathrm{U}_{2} \mathrm{~N}_{3}\left\|[001] \mathrm{UO}_{2} ; \quad \mathrm{U}_{2} \mathrm{~N}_{3}\{101\}\right\| \mathrm{UO}_{2}\{101\} \quad$ and 
$\left.\mathrm{U}_{2} \mathrm{~N}_{3}[101] \| \mathrm{UO}_{2}[101]\right)$ due to small lattice misfit $(2.3 \%)$ and small interfacial energy $\left(127 \mathrm{~mJ} / \mathrm{m}^{2}\right)$.

$\mathrm{UN}$ and $\mathrm{UO}_{2}$ have a large lattice misfit of $11.8 \%$ and form phase boundaries with a sawtooth morphology with a crystallographic orientation relationship of $[101] \mathrm{UN} \|[101] \mathrm{UO}_{2}$ and (111) $\mathrm{UN} \|(111) \mathrm{UO}_{2}$. The oxidation reactions, $\mathrm{UN}+\mathrm{O}_{2}=\mathrm{UO}_{2}+1 / 2 \mathrm{~N}_{2}$ and $3 \mathrm{UN}+\mathrm{O}_{2}=\mathrm{UO}_{2}+$ $\mathrm{U}_{2} \mathrm{~N}_{3}$ are very thermodynamically favorable and occur even at very low oxygen partial pressures due to negative energy change. In addition, these oxidation reactions are assisted by proton irradiation and the ionization of molecular oxygen to form atomic oxygen which can accelerate oxidation reactions. Irradiation creates point defects and dislocation loops, which are preferred sites for atomic diffusion.

The dislocation loops grow while their number density decreases with increasing temperature and dose. The loop sizes in the two nitride phases are over three times larger than that in $\mathrm{UO}_{2}$, while the number density in $\mathrm{UO}_{2}$ is one order of magnitude higher than that in two nitride phases. The radiation-induced loop growth resistance of three phases in the $\mathrm{UN}-5 \mathrm{UO}_{2}$ composite follows the sequence of $\mathrm{UO}_{2}>\mathrm{UN}>\mathrm{U}_{2} \mathrm{~N}_{3}$, which is governed by the mobility of uranium interstitials. The defects responsible for loop evolution are more mobile in the two nitride phases than the oxide. $\mathrm{N}$ interstitials in the two nitride phases are more mobile than oxygen interstitials in $\mathrm{UO}_{2} . \mathrm{N}$ interstitials in $\mathrm{U}_{2} \mathrm{~N}_{3}$ are less mobile than those in $\mathrm{UN}$ owing to a large interstitial site location in $\mathrm{UN}$. However, the loop growth in $\mathrm{U}_{2} \mathrm{~N}_{3}$ is faster due to lower number of recombination sites for Frenkel pair mutual recombination.

\section{Acknowledgements}

The ion irradiation and defects analysis were supported by the U.S. Department of Energy, Office of Nuclear Energy under a Nuclear Engineer University Program (award number: DE- 
NE00120690) and the ChemiSTEM characterization was supported by the Laboratory Directed Research and Development program (LDRD project \# 14-098) at Idaho National Laboratory. The DFT calculation and defect evolution modeling are supported by Center for Thermal Energy Transport Under Irradiation (TETI), an Energy Frontier Research Center funded by the U.S. Department of Energy, Office of Science, Office of Basic Energy Sciences. L. He also acknowledges the U.S. Department of Energy, Office of Nuclear Energy under DOE Idaho Operations Office Contract DE-AC07-051D14517, as part of Nuclear Science User Facility experiments. The authors thank Jonathan King at University of Wisconsin, Jatuporn Burns, Yaqiao Wu, Joanna Taylor, and Kristi Moser-McIntire at the Center for Advanced Energy Studies, and Jeffery Bailey, Jayson Bush, and JoAnn Merrill at Idaho National Laboratory for their invaluable assistance.

\section{References}

1. S.J. Zinkle, G.S. Was, Materials challenges in nuclear energy, Acta Mater. 61 (2013) 735-758.

2. T. Chen, L. He, M.H. Cullison, C. Hay, J. Burns, Y. Wu, L. Tan, The correlation between microstructure and nanoindentation propoerty of neutron-irradiated adavnced austenitic alloy D9, Acta Mater. 195 (2020) 1-13.

3. T. Allen, J. Busby, M. Meyer, D. Petti, Materials challenges for nuclear systems, Mater. Today 13 (2010) 14-23.

4. D. Zhang, C. Jin, H. Tian, Y. Xiong, H. Zhang, P. Qiao, J. Fan, Z. Zhang, Z.Y. Li, J. Li, An in situ TEM study of the surface oxidation of palladium nanocrystals assisted by electron irradiation, Nanoscale 9 (2017) 6327-6333.

5. X. Huang, T. Jones, H. Fan, M.-G. Willinger, Atomic-scale observation of irradiation-induced surface oxidation by in situ transmission electron microscopy, Adv. Mater. Inter. 3 (2016) 1600751.

6. R. Florez, M.L. Crespillo, X. He, T.A. White, G. Hilmas, W. Fahrenholtz, J. Graham, The irradiation response of $\mathrm{ZrC}$ ceramics under $10 \mathrm{MeV} \mathrm{Au}^{3+}$ ion irradiation at 800 degrees $\mathrm{C}$, J. Eur. Ceram. Soc. 40 (2020) 1791-1800.

7. R. Florez, M.L. Crespillo, X. He, T.A. White, G. Hilmas, W. Fahrenholtz, J. Graham, Early stage oxidation of $\mathrm{ZrC}$ under $10 \mathrm{MeV} \mathrm{Au}{ }^{3+}$ ion-irradiation at 800 ${ }^{\circ}$ C. Corro. Sci. 169 (2020) 108609.

8. V.V. Rondinella, T. Wiss, The high burn-up structure in nuclear fuel, Mater. Today 13 (2010) 2432.

9. M. Khafizov, M.F. Riyad, Y. Wang, J. Pakarinen, L. He, T. Yao, A. El-Azab, D. Hurley, Combining mesoscale thermal transport and x-ray diffraction measurements to characterize earlystage evolution of irradiation-induced defects in ceramics, Acta Mater. 193 (2020) 61-70. 
10. M. Khafizov, J. Pakarinen, L. He, D.H. Hurley, Impact of irradiation induced dislocation loops on thermal conductivity in ceramics, J. Am. Ceram. Soc. 102 (2019) 7533.

11. T. Deng, J. Sun, P. Tai, Y. Wang, L. Zhang, H. Chang, Z. Wang, L. Niu, Y. Sheng, D. Xue, Q. Huang, Y. Zhou, P. Song, J. Li, $\mathrm{Ti}_{3} \mathrm{AlC}_{2}$, a candidate structural material for innovative nuclear energy system: The microstructure phase transformation and defect evolution induced by energetic heavy-ion irradiation, Acta Mater. 189 (2020) 188-203.

12. A. Mostaed, G. Balakrishnan, M.R. Lees, R. Beanland, Electron-irradiation induced defects in $\mathrm{Yb}_{2} \mathrm{Ti}_{2.05} \mathrm{O}_{7}$, Acta Mater. 143 (2018) 291-297.

13. X.F. Kong, N. Gao, I.J. Beyerlein, B.N. Yao, S.J. Zheng, X.L. Ma, D. Legut, T.C. Germann, H.J. Zhang, R.F. Zhang, Interface facilitated transformation of voids directly into stacking fault tetrahedra, Acta Mater. 188 (2020) 623-634.

14. S. Agarwal, T. Koyanagi, A. Bhattacharya, L. Wang, Y. Katoh, X. Hu, M. Pagan, S.J. Zinkle, Neutron irradiation-induced microstructure damage in ultra-high temperature ceramic TiC, Acta Mater. 186 (2020) 1-10.

15. R. Mohun, L. Desgranges, C. Jegou, B. Boizot, O. Cavani, A. Canizares, F. Duval, C. He, P. Desgardin, M.-F. Barthe, P. Simon, Quantification of irradiation-induced defects in $\mathrm{UO}_{2}$ using Raman and positron annihilation spectroscopies, Acta Mater. 164 (2019) 512-519.

16. X. Wang, H. Zhang, T. Baba, H. Jiang, C. Liu, Y. Guan, O. Elleuch, T. Kuech, D. Morgan, J. Idrobo, P.M. Voyles, I. Szlufarska, Radiation-induced segregation in a ceramic, Nat. Mater. 19 (2020) 992-998.

17. Z.Q. Liu, H. Hashimoto, M. Song, K. Mitsuishi, K. Furuya, Phase transformation from $\mathrm{Fe}_{4} \mathrm{~N}$ to $\mathrm{Fe}_{3} \mathrm{O}_{4}$ due to electron irradiation in the transmission electron microsocpe, Acta Mater. 52 (2004) 1669-1674.

18. Z.Q. Liu, H. Hashimoto, E. Sukedai, M. Song, K. Mitsuishi, K. Furuya, In situ observation of the formation of $\mathrm{Fe}_{3} \mathrm{O}_{4}$ in $\mathrm{Fe}_{4} \mathrm{~N}$ (001) due to electron irradiation, Phy. Rev. Lett. 90 (2003) 255504.

19. S. Bhattacharya, X. Liu, Y. Miao, K. Mo, Z. Mei, L. Jamison, W. Mohamed, A. Oaks, R. Xu, S. Zhu, J.F. Stubbins, A.M. Yacout, Interaction between Al and atomic layer deposited (ALD) ZrN under high-energy heavy ion irradiation, Acta Mater. 164 (2019) 788-798.

20. L. He, M. Bachhav, D.D. Keiser, J.W. Madden, E. Perez, B.D. Miller, J. Gan, W. Van Renterghem, A. Leenaers, S. Van den Berghe, STEM-EDS/EELS and APT characterization of ZrN coatings on UMo fuel kernels, J. Nucl. Mater. 511 (2018) 174-182.

21. K.E. Sickafus, R.W. Grimes, J.A. Valdez, A. Cleave, M. Tang, M. Ishimaru, S.M. Corish, C.R. Stanek, B.P. Uberuaga, Radiation-induced amorphization resistance and radiation tolerance in structurally related oxides, Nat. Mater. 6 (2007) 217-223.

22. C.L. Tracy, M. Lang, J.M. Pray, F. Zhang, D. Pov, C. Park, C. Trautmann, M. Bender, D. Severin, V.A. Skuratov, R.C. Ewing, Redox response of actinide materials to highly ionizing radiation, Nat. Comm. 6 (2015) 6133.

23. H. Tagawa, Phase relations and thermodynamic properties of the uranium-nitrogen system, J. Nucl. Mater. 51 (1974) 78-89.

24. S.L. Hayes, J.K. Thomas, K.L. Peddicord, Material property correlations for uranium mononitride: I. Physical properties, J. Nucl. Mater. 171 (1990) 262-270.

25. S. Middlemas, Z. Hua, V. Chauhan, V.T. Yorgason, R. Schley, A. Khanolkar, M. Khafizov, D. Hurley, Determining local thermal transport in a composite uranium-nitride/silicide nuclear fuel using square-pulse transient thermoreflectance technique, J. Nucl. Mater. 528 (2020) 151842.

26. R.B. Matthews, Irradiation Performance of Nitride Fuels, Los Alamos National Lab., NM (United States) (1993).

27. R.B. Matthews, K.M. Chidester, C.W. Hoth, R.E. Mason, R.L. Petty, Fabrication and testing of uranium nitride fuel for space power reactors, J. Nucl. Mater. 151 (1988) 334-344.

28. R. B. Matthews, R. E. Barrs, H. T. Blair, D. P. Butt, R. E. Mason, W. A. Stark, Jr., E. K. Storms, and T. C. Wallace, Sr., "Fuels for Space Nuclear Power and Propulsion: 1983-1993," in A 
Critical Review of Space Nuclear Power and Propulsion 1984-1993, pp. 179-220, American Institute of Physics, New York, 1994. (invited chapter)

29. J.P. Gorton, B.S. Collins, A.T. Nelson, N.R. Brown, Reactor performance and safety characteristics of ThN-UN fuel concepts in a PWR, Nucl. Eng. Des. 355 (2019) 110317.

30. L.G. Gonzalez Fonseca, M. Hedberg, L. Huan, P. Olsson, T. Retegan Vollmer, Application of SPS in the fabrication of UN and (U,Th)N pellets from microspheres, J. Nucl. Mater. 536 (2020) 152181.

31. L.H. Ortega, B.J. Blamer, J.A. Evans, S.M. McDeavitt, Development of an accident-tolerant fuel composite from uranium mononitride (UN) and uranium sesquisilicide $\left(\mathrm{U}_{3} \mathrm{Si}_{2}\right)$ with increased uranium loading, J. Nucl. Mater. 471 (2016) 116-121.

32. K.A. Terrani, B.C. Jolly, J.M. Harp, Uranium nitride tristructural-isotropic fuel particle, J. Nucl. Mater. 531 (2020) 152034.

33. C.M. Silva, R.D. Hunt, L. L. Snead, K.A. Terrani, Synthesis of Phase-Pure $\mathrm{U}_{2} \mathrm{~N}_{3}$ Microspheres and Its Decomposition into UN, Inorg. Chem. 54 (2015) 293-298.

34. J. Bugl, A.A. Bauer, Corrosion and Oxidation Characteristics of Uranium Mononitride, Battelle Memorial Institute, Columbus, OH (1964).

35. J. Antill, B. Myatt, Kinetics of the oxidation of UN and $\mathrm{U}(\mathrm{CO})$ in carbon dioxide, steam and water at elevated temperatures, Corros. Sci. 6 (1966) 17-23.

36. R.M. Dell, V.J. Wheeler, N.J. Bridger, Hydrolysis of uranium mononitride, Trans. Faraday Soc. 63 (1967) 1286-1294.

37. S. Sugihara, S. Imoto, Hydrolysis of uranium nitrides, J. Nucl. Sci. Technol., 6 (1969) 237-242.

38. G.R. Rao, S. Mukerjee, V. Vaidya, V. Venugopal, D. Sood, Oxidation and hydrolysis kinetic studies on UN, J. Nucl. Mater. 185 (1991) 231-241.

39. M. Jolkkonen, P. Malkki, K. Johnson, J. Wallenius, Uranium nitride fuels in superheated steam, J. Nucl. Sci. Technol. 54 (2017) 513-519.

40. D.A. Lopes, S. Uygur, K. Johnson, Degradation of $U N$ and $U N-U_{3} \mathrm{Si}_{2}$ pellets in steam environment, J. Nucl. Sci. Technol. 54 (2017) 405-413.

41. B.J. Jaques, J. Watkins, J.R. Croteau, G.A. Alanko, B. Tyburska-Püschel, M. Meyer, P. Xu, E.J. Lahoda, D.P. Butt, Synthesis and sintering of UN-UO $\mathrm{U}_{2}$ fuel composites, J. Nucl. Mater. 466 (2015) 745-754.

42. J.K Watkins, D.P. Butt, B.J. Jaques, Microstructural degradation of UN and UN-UO2 composites in hydrothermal oxidation conditions, J. Nucl. Mater. 518 (2019) 30-40.

43. J. Zakova, J. Wallenius, Fuel residence time in BWRs with nitride fuels, Ann. Nucl. Energy 47 (2012) 182-191.

44. R. Benz, M.G. Bowman, Some phase equilibria in the uranium-nitrogen system, J. Am. Chem. Soc. 88 (1966) 264-268

45. C.L. Hoenig, Phase equilibria, vapor pressure, and kinetic studies in the uranium-nitrogen system, J. Am. Ceram. Soc. 54 (1971) 391-398.

46. X. Wang, R. Qiu, Q. Wang, L. Luo, Y. Hu, K. Liu, P. Zhang, Insights into the phase relations in a U-N system using a cluster formula, Inorg. Chem. 56 (2017) 3550-3555.

47. K. Liu, X. Wang, J. Liu, Y. Hu, H. Zhong, Q. Pan, L. Luo, S. Chen, Y. Zhang, Z. Long, Nitride layers on uranium surfaces, Prog. Sur. Sci. 93 (2018) 47-84.

48. H. Serizawa, K. Kukuda, Y. Ishii, Y. Morii, Crystallographic study on the phase transition of $\alpha$ $\mathrm{U}_{2} \mathrm{~N}_{3}$, J. Nucl. Mater. 208 (1994) 128-134.

49. G.W. Silva, C.B. Yeamans, A.P. Sattelberger, T. Hartmann, G.S. Cerefice, K.R. Czerwinski, Reaction sequence and kinetics of uranium nitride decomposition, Inorg. Chem. 48 (2009) 1063510642.

50. H. Tagawa, N. Masaki, X-ray and density studies of nonstoichiometric uranium sequinitride, J. Inorg. Nucl. Chem. 36 (1974) 1099-1103. 
51. A.K. Jiang, Y.W. Zhao, Z. Long, Y. Hu, X.F. Wang, R.L. Yang, H.L. Bao, R.G. Zeng, K.Z. Liu, Determination of interstitial oxygen atom position in $\mathrm{U}_{2} \mathrm{~N}_{3+\mathrm{x}} \mathrm{O}_{\mathrm{y}}$ by near edge structure study, $\mathrm{J}$. Nucl. Mater. 504 (2018) 215-220.

52. R.M. Dell, V.J. Wheeler, E.J. McIver, Oxidation of uranium mononitride and uranium monocarbide, Trans. Faraday Soc. 62 (1966) 3591-3606.

53. M.J. Sole, C.M. van der Walt, Oxidation and deformation studies of uranium nitride by electron microscopy, Acta Metall. 16 (1968) 501-510.

54. M. Paljevic, Z. Despotovic, Oxidation of uranium mononitride, J. Nucl. Mater. 57 (1975) 253257.

55. J.V. Dehadraya, S.K. Mukerjee, G.A. Rama Rao, V.N. Vaidya, V. Venugopal, D.D. Sood, The oxidation of uranium-cerium mononitride microspheres, J. Alloys Comp. 257 (1997) 313-321.

56. D. Bocharov, D. Gryaznov, Yu.F. Zhukovskii, E.A. Kotomin, Ab initio simulations of oxygen interaction with surfaces and interfaces in uranium mononitride, J. Nucl. Mater. 435 (2013) 102106.

57. S. Nasu, T. Kurasawa, K. Ozawa, K. Shiozawa, K. Kawatsura, K. Komaki, Proton channeling in uranium mononitride, J. Nucl. Mater. 54 (1974) 143-145.

58. A. Turos, S. Fritz, Hj. Matzke, Defects in ion-implanted uranium nitride, Phy. Rev. B 41 (1990) 3968-3977.

59. Hj. Matzke, A. Turos, Ion implantation studies of $\mathrm{UO}_{2}$ and UN, J. Nucl. Mater. 188 (1992) 285292.

60. W.J. Weber, Y. Zhang, Predicting damage production in monoatomic and multi-elemental targets using stopping and range of ions in matter code: Challenges and recommendations, Curr. Opin. Solid State Mater. Sci. 23 (2019) 100757.

61. J. Soullard, High voltage electron microscope observations of $\mathrm{UO}_{2}$, J. Nucl. Mater. 135 (1985) 190-196.

62. Y. Yang, C.A. Dickerson, T. Allen, Radiation stability of $\mathrm{ZrN}$ under $2.6 \mathrm{MeV}$ proton irradiation, J. Nucl. Mater. 392 (2009) 200-205.

63. FIZ-Karlsruhe, Inorganic crystal structures database (ICSD), 2015.

64. http://maud.radiographema.eu/

65. K. Iakoubovskii, K. Mitsuishi, Y. Nakayama, K. Furuya, Thickness measurements with electron energy loss spectroscopy, Microsc. Res. Tech. 71 (2008) 626-631.

66. J. P. Perdew, K. Burke, and M. Ernzerhof, Generalized gradient approximation made simple, Phys. Rev. Lett. 77 (1996) 3865.

67. G. Kresse and J. Furthmuller, Efficient iterative schemes for ab initio total-energy calculations using a plane-wave basis set, Phys. Rev. B 54 (1996) 11169.

68. U. Carvajal Nunez, D. Prieur, R. Bohler, D. Manara, Melting point determination of uranium nitride and uranium plutonium nitride: A laser heating study, J. Nucl. Mater. 449 (2014) 1-8.

69. L. He, M. Gupta, M.A. Kirk, J. Pakarinen, J. Gan, T.R. Allen, In situ TEM observation of dislocation evolution in polycrystalline $\mathrm{UO}_{2}$, JOM 66 (2014) 2553-2561.

70. R. Benz, G. Balog, B.H. Baca, Uranium-uranium dioxide-uranium nitride $\left(\mathrm{UN}_{2}\right)$ phase diagram, High Temp. Sci. 2 (1970) 221-251.

71. J. C. Velázquez-Altamirano, I.P. Torres-Avila,G. Teran-Méndez, S. I. Capula-Colindres, R. Cabrera-Sierra, R. Carrera-Espinoza, E. Hernández-Sánchez, A stochastic model and investigation into the probability distribution of the thickness of boride layers formed on lowcarbon steel, Coatings 9 (2019) 756.

72. V. Zhukov, I. Popova, J.T. Yates, Jr, Electron-stimulated oxidation of Al(111) by oxygen at low temperatures: Mechanism of enhanced oxidation kinetics, Phy. Rev. B 65 (2002) 195409.

73. Z.Q. Liu, H. Hashimoto, T. Sakata, H. Mori, M. Song, K. Mitsuishi, K. Furuya, Transmission electron microscopy investigation on the electron-stimulated oxidation of iron nitrides by $2-\mathrm{MeV}$ electron irradiation, J. Mater. Res. 20 (2005) 1918-1926. 
74. B. Liu, Z.L. Dong, Y. Hua, C. Fu, X. Li, P.K. Tan, Y. Zhao, Electron-beam radiation induced degradation of silicon nitride and its impact to semiconductor failure analysis by TEM, AIP Adv. 8 (2018) 115327.

75. O. Wilhelmi, K.-H. Schartner, Proton and electron impact on molecular and atomic oxygen: I. High resolution fluorescence spectra in the visible and VUV spectral range and emission crosssections for dissociative ionization and excitation of $\mathrm{O}_{2}$. Eur. Phys. J. D 11 (2000) 79-90.

76. G. Gorine, G. Pezzullo, D. Bouvet, F. Ravotti, J.-M. Sallese, Radiation enhanced oxidation of proton-irradiated copper thin films: Towards a new concept of ultra-high radiation dosimetry. AIP Adv. 9 (2019) 085217.

77. J. Wang, M.B. Toloczko, K. Kruska, D.K. Schreiber, D.J. Edwards, Z. Zhu, J. Zhang, Carbon contamination during ion irradiation-accurate detection and characterization its effect on microstructure of ferritic/martensitic steels, Sci. Rep. 7 (2017) 15813.

78. D. Gosset, M. Dollé, D. Simeone, G. Baldinozzi, L. Thomé, Structural evolution of zirconium carbide under ion irradiation. J. Nucl. Mater. 373 (2008) 123-129.

79. D. Gosset, M. Dollé, D. Simeone, G. Baldinozzi, L. Thomé, Structural behavior of nearly stoichiometric ZrC under ion irradiation. Nucl. Instru. Meth. B 266 (2008) 2801-2805.

80. C. Kinoshita, K. Hayashi, S. Kitajima, Kinetics of Point-defects in electron-irradiated MgO, Nucl. Instrum. Meth. B 1 (1984) 209-218.

81. M. Kiritani, N. Yoshida, H. Takata, Y. Maehara, Growth of interstitial type dislocation loops and vacancy mobility in electron-irradiated metals, J. Phy. Soc. Japan 38 (1975) 1677-1686.

82. A.I. Ryazano, C. Kinoshita, Growth kinetics of dislocation loops in irradiated ceramic materials, Nucl. Instrum. Meth. B 191 (2002) 65-73.

83. S.I. Golubov, A.V. Barashev, R.E. Stoller, Radiation damage theory in R.J. M. Koninges (Ed.), Comprehensive Nuclear Materials, Elsevier, Amsterdam (2012), vol. 1, pp. 357-391.

84. D.R. Olander, Fundamental aspects of nuclear reactor fuel elements, energy research and development administration, technical information center TID-26711, 1976.

85. D.A. Andersson, M.R. Tonks, L. Casillas, S. Vyas, P. Nerikar, B.P. Uberuaga, C.R. Stanek, Multiscale simulation of xenon diffusion and grain boundary segregation in $\mathrm{UO}_{2}$, J. Nucl. Mater, 462 (2015) 15-25.

86. S. Khalil, T. Allen, A. El-Azab, Off-stoichiometric defect clustering in irradiated oxides, Chem. Phys. 487 (2017) 1-10.

87. Y. Miao, K.A. Gamble, D. Andersson, B. Ye, Z. Mei, G. Hofman, A.M. Yacout, Gaseous swelling of $\mathrm{U}_{3} \mathrm{Si}_{2}$ during steady-state LWR operation: A rate theory investigation, Nucl. Eng. Design 322 (2017) 336-244

88. C. Dennett, Z. Hua, A. Khanolkar, T. Yao, P. Morgan, T. Prusnick, N. Poudel, A. French, K. Gofryk, L. He, L. Shao, M. Khafizov, J. Mann, D. Hurley, The influence of lattice defects, recombination, and clustering on thermal transport in single crystal thorium dioxide, APL Mater. 8 (2020) 111103.

89. L. He, M. Gupta, C.A. Yablinsky, J. Gan, M.A. Kirk, X.-M. Bai, J. Pakarinen, T.R. Allen, In situ TEM observation of dislocation evolution in Kr-irradiated $\mathrm{UO}_{2}$ single crystal, J. Nucl. Mater. 443 (2013) 71-77.

90. C. Onofri, C. Sabathier, C. Baumier, C. Bachelet, H. Palancher, M. Legros, Evolution of extended defects in polycrystalline Au-irradiated $\mathrm{UO}_{2}$ using in situ TEM: temperature and fluence effects, J. Nucl. Mater. 482 (2016) 105-113. 